\title{
Children's Emotion Regulation Scale in Mathematics (CERS-M): Development and Validation of a Self-Reported Instrument
}

\author{
Vanessa Hanin'1, Jacques Grégoire1, Moïra Mikolajczak², \\ Carole Fantini-Hauwel $^{3}$, Catherine Van Nieuwenhoven ${ }^{1}$ \\ ${ }^{1}$ Department of Education Science, Université Catholique de Louvain, Louvain, Belgium \\ ${ }^{2}$ Department of Psychology, Université Catholique de Louvain, Louvain, Belgium \\ ${ }^{3}$ Department of Psychology, Université Libre de Bruxelles, Bruxelles, Belgium \\ Email: vanessa.hanin@uclouvain.be
}

How to cite this paper: Hanin, V., Grégoire, J., Mikolajczak, M., Fantini-Hauwel, C., \& Van Nieuwenhoven, C. (2017). Children's Emotion Regulation Scale in Mathematics (CERS-M): Development and Validation of a Self-Reported Instrument. Psychology, 8, 2240-2275.

https://doi.org/10.4236/psych.2017.813143

Received: April 14, 2017

Accepted: November 27, 2017

Published: November 30, 2017

Copyright $\odot 2017$ by authors and Scientific Research Publishing Inc. This work is licensed under the Creative Commons Attribution International License (CC BY 4.0).

http://creativecommons.org/licenses/by/4.0/

(c) $\underset{\mathrm{EY}}{\mathrm{B}}$ Open Access

\begin{abstract}
This article introduces the development and validation of a self-report questionnaire: the Children's Emotion Regulation scale in Mathematics (CERSM). Results highlighted a) through exploratory and confirmatory factor analyses, a meaningful six-factor model (emotion expression, task utility selfpersuasion, help-seeking, negative self-talk, brief attentional relaxation, and dysfunctional avoidance); b) satisfactory internal reliabilities; c) test-retest reliability scores indicative of a satisfactory stability of the measures over time; d) preliminary evidence of convergent and discriminant validity with CERS$M$ being very weakly linked to verbal skill and moderately to emotion regulation strategies measured through the Flemish version of the COPE-questionnaire; e) preliminary evidence of criterion validity, with CERS-M scores predicting math anxiety, and to a lesser extent, students' performance; f) preliminary evidence of incremental validity, with the CERS-M predicting math anxiety and performance over and above emotion regulation measured by the COPEquestionnaire. Findings constitute encouraging preliminary psychometric characteristics in favor of the use of the CERS-M.
\end{abstract}

\section{Keywords}

Scale Development, Emotion Regulation, Evidence of Validity and Reliability, Mathematics Problem-Solving, Upper Elementary Students

\section{Introduction}

International mathematics tests have showed insufficient mastery of basic skills 
for a large number of primary and secondary school students (OECD, 2014; OECD, 2016). This alarming observation drove researchers to investigate the dimensions at the core of mathematical learning and achievement. There is general agreement that mathematical learning brings into close interaction motivational, cognitive and affective processes and their regulation (e.g., Ahmed, Minnaert, Van der Werf, \& Kuyper, 2013; Hanin \& Van Nieuwenhoven, 2016; Linnenbrink, 2006; Op’t Eynde, De Corte, \& Verschaffel, 2006). Although researchers began to study emotions only recently, compared to motivational and cognitive dimensions, the impact of emotions on students' learning and performance has been largely demonstrated (e.g., Ahmed et al., 2013; Hanin \& Van Nieuwenhoven, 2016; Isen, 2000; Pekrun, 2006). In this respect, emotions are known to influence the quantity of cognitive resources available, the intrinsic and extrinsic motivation to learn, the kind of learning strategies used and the development of self-regulation skills (Isen, 2000; Mikolajczak, 2012; Pekrun, 2006). More precisely, regarding the cognitive dimension, on the whole, positive emotions promote the use of flexible and creative learning strategies, in-depth cognitive processing, and self-regulated behaviors. In contrast, negative emotions are associated with the use of more rigid strategies, superficial cognitive processing and external guidance. As emotions are organized in a domain-specific way (Goetz, Frenzel, Pekrun, \& Hall, 2006; Goetz, Frenzel, Pekrun, Hall, \& Lüdtke, 2007), one academic domain, particularly affected by emotions, i.e., mathematics, has been retained for the present study.

Researchers have shown that students almost always experience negative emotions in mathematical settings, e.g., anxiety, anger, hopelessness, shame, boredom, frustration, concern and nervousness (Ahmed et al., 2013; Goetz, Haag, Lipnevitch, Keller et al., 2014; Op't Eynde, De Corte, \& Mercken, 2004). Since negative emotions impair academic achievement, it is of great importance to help students regulate them, that is, to "influence which emotions they have, when they have them, and how they experience and express these emotions" (Gross, 1998: p. 275). Yet, according to a study conducted by De Corte, Depaepe, Op't Eynde \& Verschaffel (2011), students between the ages of 14 and 16 have a poor track record of emotion regulation when solving complex mathematical tasks. "As a consequence, they risk ending up in a negative spiral where the use of inappropriate regulation strategies results in weak performance, and, thus in experiencing even more stress" (De Corte et al., 2011: p. 490). Emotion regulation affects not only students' academic performance but also the main domains of their life, i.e. mental health (Eisenberg, Cumberland, Spinrad, Fabes et al., 2001; Extremera, Duran, \& Rey, 2007), physical health (Housiaux, Luminet, Van Broeck, \& Dorchy, 2010; Rieffe, Terwogt, Petrides, Cowan et al., 2007), and social relationships (Denham, McKinley, Couchoud, \& Holt, 1990; Pons, Doudin, Harris, \& de Rosnay, 2002).

The significant position filled by emotions in an individual's life is attracting the attention of an increasing number of researchers. More and more scholars are becoming interested in how individuals cope with emotion-eliciting situa- 
tions. As a result, several instruments measuring emotion regulation in adults have emerged in recent years (e.g., Freudenthaler \& Neubauer's Emotion Management Abilities test, 2007; Garnefski \& Kraaij's Cognitive Emotion Regulation Questionnaire, 2007; Mayer, Salovey, \& Caruso's Emotional Intelligence Test, 2002; Nelis, Quoidbach, Hansenne, \& Mikolajczak's Emotion Regulation ProfileRevised, 2011). But such instruments are scarcer for children and teenagers. Indeed, to our knowledge, only two such instruments exist. One is the self-reported Cognitive Emotion Regulation Questionnaire (CERQ-kids) which appraises what children aged between 9 and 12 years think after the experience of threatening or stressful events (Garnefski, Rieffe, Jellesma, Terwogt et al., 2007). This scale measures nine emotion regulation strategies, namely, self-blame, other- blame, rumination, catastrophizing, positive refocusing, planning, positive reappraisal, putting into perspective, and acceptance, through 36 items. The second instrument is the Flemish version of the COPE-questionnaire. This coping inventory was initially drafted by Carver, Scheier, \& Weintraub (1989) and has been adapted by De Corte et al. (2011) to the school context, specifically to schoolrelated mathematical activities-a difficult test, a difficult mathematics homework and a difficult mathematics lesson-and to secondary graders. This instrument encompasses 15 coping dimensions, namely, active coping, planning, suppression of competing activities, restraint coping, seeking social support for instrumental reasons, seeking social support for emotional reasons, positive reinterpretation and growth, acceptance, turning to religion, focus on and venting emotions, denial, behavioral disengagement, mental disengagement, alcohol-drug disengagement, and joking, operationalized through 60 items.

However, these two scales display several limits. First, the CERQ-kids is contextless. Yet, as emotions are context-dependent (Frijda, 1993; Goetz et al., 2007; Goetz, Pekrun, Hall, \& Haag, 2006), emotion regulation strategies need to be considered in this way as well. Second, the design of this instrument retains the same factorial structure as the one used for the adult version. This implies that the nine coping strategies appraised may not necessarily be meaningful for children or that specific child-related coping strategies might have been overlooked. This observation also concerns the Flemish version of the COPE-questionnaire. Although this questionnaire takes the situational nature of emotion regulation strategies into account, in that it rests on the original coping dimensions, it doesn't entirely fit elementary and secondary children's reality. Above all, the two scales are based on a single theoretical approach, i.e., the literature on stress and coping, so covering only one area of research on emotion regulation. Hence there is a lack of an instrument that simultaneously reflects elementary and secondary students' reality, that assesses emotion regulation strategies in context, and that considers the variety of the theoretical approaches used to investigate this subject. Such an instrument would be valuable for both educational research and practice. Regarding the former, as mentioned previously, emotional competencies and, particularly, emotion regulation occupy an increasingly important 
place in academic learning and achievement research. So it becomes important to have adequate and valid instruments to measure these constructs. Concerning educational practice, given the key role played by emotion regulation in an individual's life, it appears important to have a more fine-grained knowledge of student's emotion regulation strategies in order to help them in an effective way. The present paper endorses this perspective by describing the development and the process of validation of a self-reported scale which assesses the emotion regulation strategies used by upper elementary students to manage their emotions when solving a math problem. This scale has been named: "Children's Emotion Regulation Scale in Mathematics (CERS-M)".

In the following sections, we first outline the theoretical framework underlying the construction of the CERS-M. Next, we describe the procedure of construction of the CERS-M. A first study then examines the descriptive properties, the internal consistency, and the factor structure of the CERS-M. Subsequently, a second study aims to provide additional evidence of both the reliability and the validity of the scale. Finally, a discussion about the findings closes this paper.

\section{Brief Background to Inventories of Emotion Regulation Strategies}

Numerous researchers in psychology and psychopathology have examined the responses of individuals in coping with emotion-filled situations (e.g., Ayers, Sandler, West, \& Roosa, 1996; Carver et al., 1989; Endler \& Parker, 1990; Freud 1896/2000; Garnefski, Kraaij, \& Spinhoven, 2001; Lazarus \& Folkman, 1984; Parkinson \& Totterdell, 1999). Each scholar has investigated and categorized these responses based on his/her own research paradigm(s). Consequently, the literature abounds in different nomenclatures. These various nomenclatures fall, in reality, within three main research traditions, namely, the psychoanalytic tradition (Freud, 1896/2000), the stress and coping tradition (e.g. Lazarus \& Folkman, 1984), and the emotion regulation tradition (e.g. Fredrickson, Mancuso, Branigan, \& Tugade, 2000; Gross, 1998; Mikolajczak, Quoidbach, Kotsou, \& Nélis, 2009; Parkinson \& Totterdell, 1999). Note that the second research tradition has its roots in the first and that the last borrowed heavily from the first two (Gross, 1998).

Recently, Mikolajczak (2012) attempted to integrate, within a unique model, these various nomenclatures. Selected strategies are those presenting the strongest effects for the biggest number of individuals, in the widest range of situations. These strategies have been classified on the basis of the emotion-generative process defined by Gross (1998) because this wins unanimous support among scholars. According to Gross (1998), each component of an emotional experience can be the object of regulation. Five families of strategies were so defined: situation selection, situation modification, attentional deployment, cognitive change, and response modulation. Mikolajczak et al. (2009) added a sixth family called "emotion expression". Each family includes both functional strategies, 
that is, strategies that are beneficial in maintaining mental health, physical health, quality of social relationships and academic performance and dysfunctional strategies, namely, strategies that impair these dimensions (Gross, 1998; Mikolajczak et al., 2009). In addition, it is noteworthy that the strategies belonging to the same family are independent constructs.

\section{Emotion Regulation Strategies Inventory Used in the Present Study}

In order to stay consistent with an academic context of compulsory schooling, we made some adjustments to Mikolajczak's inventory. Firstly, we removed two functional strategies (i.e. mindfulness, and directed relaxation) and three dysfunctional strategies (i.e. dysfunctional confrontation, denial, and alcohol-anxiolytic abuse). Secondly, we reconceptualized the acceptance dimension, which was initially associated to painful events (e.g. rape, genocide). Finally, we split the distraction dimension into a functional side and a dysfunctional side. Table 1 summarizes the nineteen strategies selected for the present study. These strategies are detailed hereafter.

\subsection{Situation Selection}

This family of strategies aims to reduce as much as possible the probability of being in a situation that, at the same time, generates unpleasant emotions and lacks long-term benefits (Gross, 1998; Mikolajczak, 2012). Functional confrontation consists in confronting oneself with short-term negative emotion-eliciting situations that are associated with long-term benefits (e.g., concentrating on math exercises even if it makes one angry, anxious or bored because it will be useful for the exam). The corollaries are the systematic avoidance of situations that generate short-term negative emotions but that are beneficial in the long run, namely, dysfunctional avoidance (e.g., watching TV instead of doing one's homework) or postponing what could be done immediately, namely, procrasti-

Table 1. Emotion regulation strategies examined in the present study.

\begin{tabular}{|c|c|c|}
\hline Family of strategies & Functional strategy & Dysfunctional strategy \\
\hline Situation selection & - Functional confrontation & $\begin{array}{l}\text { - Dysfunctional avoidance } \\
\text { - Procrastination }\end{array}$ \\
\hline Situation modification & $\begin{array}{l}\text { - Direct modification } \\
\text { - Indirect modification }\end{array}$ & - Learned helplessness \\
\hline Attentional deployment & - Positive distraction & $\begin{array}{l}\text { - Negative distraction } \\
\text { - Rumination }\end{array}$ \\
\hline Cognitive change & $\begin{array}{l}\text { - Positive reappraisal } \\
\text { - Acceptance }\end{array}$ & $\begin{array}{l}\text { - Catastrophizing } \\
\text { - Blaming others }\end{array}$ \\
\hline Response modulation & - Relaxation & - Emotion deletion \\
\hline Emotion expression & - Social sharing & $\begin{array}{l}\text { - Unsuitable expression } \\
\text { - Verbal aggression } \\
\text { - Social withdrawal }\end{array}$ \\
\hline
\end{tabular}


nation (e.g., postponing math exercises so as not to experience an unpleasant time).

\subsection{Situation Modification}

The aim of this second family of strategies is to get rid of unpleasant emotions by solving the problem that causes them (Gross, 1998; Lazarus \& Folkman, 1984; Mikolajczak, 2012). Direct modification involves the undertaking of practical actions to influence the situation directly (e.g., to change a solving strategy when one realizes that the current one isn't working). When the intervention of a third person is necessary, we talk about indirect modification (e.g., seeking help from the teacher to solve the problem at hand). However, some individuals are convinced that they have no control over the situation and that any attempt to get by will be fruitless. This dysfunctional strategy is called learned helplessness.

\subsection{Attentional Deployment}

This third group aims at escaping the trap of selective attention induced by emotions. In this respect, positive emotions are known to focus the individual's attention on positive aspects of the situation whereas negative emotions focus it on negative aspects (Borkovec, William, \& Stöber, 1998; Gross, 1998). Positive distraction can be a functional strategy when it is used for a short period of time to relax attention (e.g., to take short breaks, such as looking out the window or stretching during a task's achievement). However, distraction can also be used in a damaging way when the student chooses deliberately to occupy his mind with something else or to undertake another activity than the one suggested by the teacher (e.g., talking, drawing, looking out the window for a long time). Further, when the learner constantly repeats the same negative thoughts and events without acting (e.g., finding it difficult to focus on the math problem because of negative thoughts such as "I'll fail"; "I suck at math"), we speak of rumination.

\subsection{Cognitive Change}

Strategies belonging to the cognitive change family are based on the principle that it is the perception that the individual makes of the situation and not the situation itself that triggers emotions (Frijda, 1986; Lazarus \& Folkman, 1984). Positive reappraisal involves altering one's perception of a given situation by considering the arguments that contradict one's thoughts and feelings, by putting things into perspective, by looking for positive aspects, by separating thought and reality or by seeking long-term benefits (e.g., when struggling with a math exercise, saying to oneself that it is not the end of the world, that it is only an exercise). If it is not possible for the individual to positively reappraise the situation, he might accept it. Acceptance involves accepting the experience of negative emotions while solving math tasks, and listening to the message conveyed by these unpleasant emotions (e.g., thinking that feeling angry, sad or disappointed is normal and is due to the fact that one didn't practice enough). 
Conversely, catastrophizing involves dramatizing the current situation or predicting the bad sides of future situations (e.g. thinking that it is terrible to not be able to solve a math problem and that we are the only one in that situation). Blaming others consists in unjustly blaming someone for the situation itself or for one's inability to solve it (e.g., thinking that if one cannot solve the problem it is because it is too hard) (Mikolajczak et al., 2009).

\subsection{Response Modulation}

This family involves the modulation of the bodily component of the emotion by acting directly on the body itself (Gross, 1998). Relaxation is apparent through taking a deep breath, neck relaxation, stretching arms, etc. Conversely, some individuals hide the visible manifestations of their emotions; this is called emotional deletion.

\subsection{Emotion Expression}

This last family of strategies consists in sharing one's emotions with others. It is noteworthy that, unlike the public opinion, social sharing of emotions doesn't have any cathartic effect (i.e., getting it off one's chest) (Rimé, 2005). However, this behavior is beneficial because it is associated to several indirect effects such as the construction or consolidation of social bonds, the expression of esteem, the transmission of affection and warmth, and assistance (Rimé, 2005). Unsuitable expression refers to expressing oneself in a way that is unacceptable to the interlocutor or at the wrong time (e.g., crying or panicking visibly when one cannot solve a math task). A particular and rather common kind of unsuitable expression is verbal aggression (e.g., expressing anger by crumpling sheets of paper, responding aggressively, by kicking one's desk). Social withdrawal consists in withdrawing from the situation. This strategy is judged harmful when the withdrawal endures and is not used to put things into perspective (e.g., refusing the teacher's help in solving a math task).

\section{Study 1}

This first study describes the procedure of construction of the CERS-M and investigates the validity of construct as well as the reliability of the instrument.

\subsection{Method}

\subsubsection{Participants}

Data collection took place in October 2014. A first sample of 63 French-speaking $5^{\text {th }}$ and $6^{\text {th }}$ graders (29 girls, mean age: $10.5 \pm 0.62$ years) (sample 1 ) from two Belgian elementary schools took part in the preliminary procedures. Two other samples of French-speaking $5^{\text {th }}$ and $6^{\text {th }}$ graders were then created. One was for the exploratory analysis $\left(\mathrm{N}=561^{1}, 275\right.$ girls, mean age: $11 \pm 1.1$ years) (sample 2 ) and the other for the confirmatory analysis $(\mathrm{N}=568,390$ girls, mean age: 10.8 \pm 1.1 years) (sample 3). Individuals from both samples came from 15 schools

${ }^{1}$ We opted for the suppression of missing data. 
which best represent the population in terms of geographical localization (five out of the six French-speaking geographical areas were represented), educational network (the three existing networks-that is, free subsidized education, officially subsidized education, and education organized by the Wallonia-Brussels federation-were represented) and socioeconomic index (low, moderate and high index ${ }^{2}$ were covered).

\subsubsection{Procedure for Items Generation}

As a first step, and in order to illustrate the emotion regulation strategies by situations and terms which speak to $5^{\text {th }}$ and $6^{\text {th }}$ graders, and, thereby, provide ecological validity, we interviewed $405^{\text {th }}$ and $6^{\text {th }}$ graders in groups of five to six students, drawn from sample 1. Then, on the basis of these interviews, on Mikolajczak's theoretical conceptualization of emotion regulation strategies, and on existing instruments (i.e. the CERQ-child, the COPE-questionnaire and the Emotion Regulation Profile-Revised), a first draft of the CERS-M was generated. It was submitted to the whole sample 1 of students to check for understandability and clarity. The items were adapted in the light of students' comments, which were mostly about the vocabulary used, and a new draft of the questionnaire was produced. This self-reported instrument measures nineteen strategies (11 dysfunctional and 8 functional), through 57 items. Each strategy is defined by three items in order to have a correct measure of it while keeping the questionnaire an accessible length. Students were asked to indicate on a 4 point Likert scale $(1=$ never to $4=$ almost always) to what extent a statement was representative of their behavior during mathematical problem solving.

\subsubsection{Procedure for Items Completion}

The respondents were solicited by their teacher, during the math course, to fill in the CERS-M in a paper and pencil format. After explaining the aim of the study and the instructions, the teacher read the items, one by one, leaving a few second between two items for students to respond. It makes it possible no to disadvantage students with reading difficulties. The duration of completing the CERS-M did not exceed 15 minutes. The teacher was allowed to answer any questions.

\subsection{Results}

\subsubsection{Descriptive Analysis}

Mean and standard deviation as well as the Skewness and the Kurtosis of the 19 subscales of the CERS-M are reported in Table 2. First, it appears that functional strategies are quite often used by $5^{\text {th }}$ and $6^{\text {th }}$ graders in math problem solving whereas dysfunctional strategies are used only occasionally. The most often used functional strategies were functional confrontation, direct modification and positive reappraisal, all of which focus on the task; the least used functional strategies were social sharing and acceptation, which concentrate on the emotion it-

${ }^{2}$ This index ranges between 1 and 20 and is based on five factors: per capita income, parents' educational level, the unemployment rate, occupational activities and comfort of housing, Belgian Official Gazette (2009). 
Table 2. Mean and standard deviations, Skewness, and Kurtosis of the 19-factor structure of the CERS-M.

\begin{tabular}{|c|c|c|c|c|}
\hline Subscale & $M$ & $S D$ & Skewness & Kurtosis \\
\hline Functional strategies & 2.31 & 0.37 & 0.04 & 0.37 \\
\hline Functional confrontation & 2.94 & 0.74 & -0.38 & -0.45 \\
\hline Direct modification & 2.82 & 0.67 & -0.29 & -0.24 \\
\hline Indirect modification & 2.31 & 0.70 & 0.33 & -0.29 \\
\hline Positive distraction & 2.18 & 0.75 & 0.43 & -0.32 \\
\hline Positive reappraisal & 2.79 & 0.69 & -0.27 & -0.41 \\
\hline Acceptance & 1.81 & 0.71 & 0.80 & 0.08 \\
\hline Relaxation & 2.19 & 0.71 & 0.37 & -0.39 \\
\hline Social sharing & 1.46 & 0.58 & 1.47 & 1.98 \\
\hline Dysfunctional strategies & 1.73 & 0.44 & 0.89 & 0.64 \\
\hline Dysfunctional avoidance & 1.46 & 0.60 & 1.67 & 2.00 \\
\hline Procrastination & 1.80 & 0.69 & 0.80 & 0.19 \\
\hline Learned helplessness & 1.69 & 0.69 & 1.12 & 0.84 \\
\hline Negative distraction & 1.69 & 0.65 & 1.04 & 0.77 \\
\hline Rumination & 1.68 & 0.70 & 1.19 & 0.96 \\
\hline Catastrophizing & 1.95 & 0.80 & 0.87 & 0.06 \\
\hline Blaming others & 1.98 & 0.59 & 0.58 & 0.47 \\
\hline Emotion deletion & 1.97 & 0.80 & 0.62 & -0.031 \\
\hline Unsuitable expression & 1.62 & 0.61 & 1.23 & 1.43 \\
\hline Verbal aggression & 1.40 & 0.57 & 1.86 & 2.66 \\
\hline Social withdrawal & 1.76 & 0.62 & 0.88 & 0.59 \\
\hline
\end{tabular}

Note. $\mathrm{N}=561 . \mathrm{M}=$ mean; $\mathrm{SD}=$ standard deviation.

self. With respect to dysfunctional strategies, these are used at with a similar frequency by the students. In addition, the statistics of distribution shape reveal, on the whole, a normal distribution of the data (Field, 2009; Gravetter \& Wallnau, 2014).

\subsubsection{Exploratory Factor Analysis}

The exploratory factor analysis examines the internal structure of the questionnaire and, more precisely, checks the adjustment between the data collected and the theoretical model on which the questionnaire is based (Laveault \& Grégoire, 2014). In the present study, the exploratory factor analysis tests if the nineteen subscales is a valid structure for upper elementary school students, using the second sample $(\mathrm{N}=561)$. Principal axis factoring was selected as the method of extraction. As we expected the nineteen factors to be correlated, we chose Oblimin with Kaiser normalization for factor rotation (Field, 2009). At first, we did not limit the number of factors extracted so as not to influence the data's struc- 
ture. The Scree plot and Kaiser's eigenvalue extraction criteria suggested the presence of between six and eight factors. In order to determine the correct number of factors, we applied parallel analysis to our data set. This method is considered as the most reliable procedure to determine the correct number of factors (Hayton, Allen, \& Scarpello, 2004). The analysis highlighted 6 factors (the first six eigenvalues were 11.4, 4.2, 2.4, 2.2, 1.7, 1.6) accounting for $41.2 \%$ of the total variance. On the basis of this information, we once again subjected the 57 items to a principal axis factor and, this time, we limited to six the number of factors extracted. The factor pattern matrix is presented in Table 3.

The following criteria were used to refine our results. First, an item was judged to belong to a factor if its loading on this specific factor was above or equal to.50. Second, if an item was loading above.30 on more than one factor, it was removed (Brown, 2006). The six factors extracted were labeled according to the items they covered. The first group of items (see Table 3 ) pertains to the expression of emotions either in an appropriate way (social sharing) or in an inappropriate way (unsuitable expression and verbal aggression), and therefore was called "emotion expression". The second group of items, was labeled "task utility self-persuasion", in reference to Eccles, Wigfield, Harold, \& Blumenfeld (1993) conceptualization of task value because it gathers items which aim at convincing oneself of the personal utility of the task despite the fact that the latter generates unpleasant emotions. The third group of items covers strategies that focus on the negative aspects of the situation, by dramatizing them (catastrophizing), by constantly thinking them over (rumination) or by convincing oneself that they are beyond one's control (learned helplessness) and this third group was therefore called "negative self-talk". The fourth group of items is about seeking or rejecting peer and teacher assistance and, therefore, was labeled "help seeking". The fifth group was named "brief attentional relaxation" because it encompasses strategies ${ }^{3}$ aiming to release attention for a few seconds by distracting or by relaxing. The sixth and last group of items includes strategies that consist in avoiding dealing with the task, despite the fact that its completion is beneficial in the long run, and therefore was called "dysfunctional avoidance".

The discrepancy between the internal structure highlighted by the previous analysis (6 factors) and our theoretical expectations (19 factors) is discussed later on in this paper.

\subsubsection{Internal Consistency}

The internal consistency of the CERS-M global score was good ( $\alpha=0.82$ ). Cronbach's alphas performed on the six subscales indicated satisfactory to good internal consistency (see Table 4).

\subsubsection{Confirmatory Factor Analysis}

Confirmatory factor analysis was applied to our third data set $(\mathrm{N}=568)$ in order

${ }^{3}$ The fact that the item "Unsuitable expression 3" is loading on the "brief attentional relaxation" factor could seem odd at first sight but is, actually, quite relevant when we looked at the wording of the item: "I breathe a lot when I try to solve a math problem". 
Table 3. Factor pattern Matrix for the CERS-M items.

\begin{tabular}{|c|c|c|c|c|c|c|}
\hline \multirow{2}{*}{ Item } & \multicolumn{6}{|c|}{ Factor } \\
\hline & Factor 1 & Factor 2 & Factor 3 & Factor 4 & Factor 5 & Factor 6 \\
\hline Social sharing 2 & 0.69 & 0.03 & 0.17 & 0.07 & -0.05 & 0.10 \\
\hline Social sharing 1 & 0.62 & 0.02 & 0.14 & 0.10 & -0.03 & 0.08 \\
\hline Unsuitable expression 2 & 0.57 & -0.14 & -0.05 & 0.11 & 0.21 & 0.21 \\
\hline Verbal aggression 1 & 0.53 & -0.21 & 0.11 & -0.10 & 0.20 & 0.26 \\
\hline Functional confrontation 3 & -0.04 & 0.70 & 0.04 & 0.05 & 0.07 & 0.05 \\
\hline Functional confrontation 2 & 0.04 & 0.67 & 0.02 & 0.09 & 0.03 & 0.05 \\
\hline Positive reappraisal 2 & 0.00 & 0.66 & 0.01 & 0.18 & 0.03 & -0.01 \\
\hline Direct modification 3 & -0.07 & 0.58 & -0.07 & 0.03 & 0.06 & -0.15 \\
\hline Direct modification 2 & -0.15 & 0.58 & -0.09 & 0.00 & 0.07 & -0.01 \\
\hline Catastrophizing 3 & 0.12 & 0.04 & 0.72 & 0.06 & 0.14 & 0.11 \\
\hline Catastrophizing 2 & 0.13 & -0.03 & 0.69 & -0.04 & 0.17 & 0.16 \\
\hline Learned helplessness 1 & 0.17 & -0.16 & 0.63 & 0.06 & 0.05 & 0.09 \\
\hline Learned helplessness 3 & 0.16 & -0.16 & 0.62 & 0.12 & 0.06 & 0.25 \\
\hline Rumination 1 & 0.23 & -0.09 & 0.60 & 0.19 & 0.11 & 0.15 \\
\hline Catastrophizing 1 & 0.11 & -0.10 & 0.60 & 0.09 & 0.09 & 0.06 \\
\hline Rumination 3 & 0.37 & -0.05 & 0.50 & -0.13 & 0.11 & 0.24 \\
\hline Indirect modification 1 & 0.14 & 0.10 & 0.11 & 0.69 & 0.07 & 0.19 \\
\hline Indirect modification 2 & 0.15 & 0.27 & 0.02 & 0.68 & 0.10 & 0.18 \\
\hline Social withdrawal 1 & 0.14 & -0.01 & -0.02 & -0.64 & 0.05 & 0.00 \\
\hline Positive distraction 1 & 0.04 & 0.00 & 0.16 & 0.16 & 0.65 & 0.04 \\
\hline Positive distraction 2 & -0.00 & 0.07 & 0.19 & 0.06 & 0.64 & 0.19 \\
\hline Relaxation 3 & 0.08 & 0.03 & 0.01 & -0.13 & 0.63 & -0.01 \\
\hline Positive distraction 3 & 0.10 & -0.02 & 0.17 & 0.10 & 0.60 & 0.24 \\
\hline Unsuitable expression 3 & 0.29 & -0.04 & 0.24 & 0.10 & 0.53 & 0.15 \\
\hline Relaxation 2 & 0.12 & 0.15 & 0.01 & -0.12 & 0.52 & 0.12 \\
\hline Procrastination 2 & 0.00 & -0.17 & 0.15 & 0.11 & 0.17 & 0.60 \\
\hline Procrastination 1 & 0.06 & -0.17 & 0.17 & 0.10 & 0.05 & 0.58 \\
\hline Dysfunctional avoidance 2 & 0.37 & -0.31 & 0.18 & -0.02 & 0.10 & 0.56 \\
\hline Procrastination 3 & 0.04 & -0.06 & 0.32 & 0.01 & 0.21 & 0.54 \\
\hline Dysfunctional avoidance 1 & 0.24 & -0.23 & 0.16 & 0.01 & 0.01 & 0.51 \\
\hline
\end{tabular}

Note. $\mathrm{N}=561$.

Table 4. Internal consistency of the six factors extracted.

\begin{tabular}{cc}
\hline Factor & Alpha \\
\hline Emotion expression & 0.68 \\
Task utility self-persuasion & 0.76 \\
Negative self-talk & 0.83 \\
Help seeking & 0.67 \\
Brief attentional relaxation & 0.75 \\
Dysfunctional avoidance & 0.76 \\
\hline
\end{tabular}

Note. $\mathrm{N}=561$. 
to assess if the structure in six factors, highlighted by the exploratory factor analysis, fitted best with the data, as compared to alternative models. Therefore confirmatory analyses were performed using Maximum Likelihood estimations with AMOS 22 (IBM Inc.). Scholars recommend the use of several fit indices to gauge the quality of the adjustment (Byrne, 2016; Hu \& Bentler, 1999; Laveault \& Grégoire, 2014). In this respect, they distinguish, among others, absolute fit indices which compare the hypothesized model with no model at all, comparative or incremental indices of fit which use a baseline model for assessing model fit, and parsimony fit indices which penalize for model complexity (Byrne, 2016). The most commonly used goodness-of-fit statistics were used in the present study (Byrne, 2016; Laveault \& Grégoire, 2014), that is, the chi-square to its degrees of freedom ( $\chi^{2} / \mathrm{df}$; a $\chi^{2} / \mathrm{df}$ close to or less than 2.0 was considered to be indicative of a good model fit, and close to or less than 5.0 as indicative of a satisfying fit); the Root Mean Square Error of Approximation (RMSEA; good fit $<0.05$, satisfying fit $<0.08$ ); the Standardized Root Mean Square Residual (SRMR; good fit $<0.05$, satisfying fit $<0.08$ ); the Comparative Fit Index (CFI; good fit $\geq 0.95$; satisfying fit $\geq 0.90$ ), and the adjusted goodness of fit index (AGFI; good fit $\geq 0.95$; satisfying fit $\geq 0.90$ ) (Hu \& Bentler, 1999).

Before presenting the different models, let us note that on the basis of high modification indices and low items factor loadings (Byrne, 2016) several items were removed from the model that emerged from the exploratory factor analysis. This made it possible to have an equivalent number of items per factor, three to be precise, which is recommended by Laveault and Grégoire (2014).

Model 1 is a model with six first-order factors (i.e., emotion expression, task utility self-persuasion, negative self-talk, help seeking, brief attentional relaxation, dysfunctional avoidance). This model encompasses three items per factor for a total of 18 items (see Figure 1).

Model 2 is a model with two second-order factors (i.e., functional strategies, and dysfunctional strategies) and nineteen dimensions (i.e., functional confrontation, direct modification, indirect modification, positive distraction, positive reappraisal, acceptance, relaxation, social sharing, dysfunctional avoidance, procrastination, learned helplessness, negative distraction, rumination, catastrophizing, blaming others, emotion deletion, unsuitable expression, verbal aggression, and social withdrawal), each operationalized by three items. This model represents the theoretical model of Mikolajczak (2012) in all its complexity (see Figure 1).

Model 3 is a model with nineteen first-order factors (the same as for model 2). This model reflects the theoretical model of Mikolajczak (2012) as it is commonly used by scholars (Leroy, Boudrenghien, \& Grégoire, 2013; Nelis et al., 2011) (see Figure 1).

Model 4 encompasses the six families of emotion regulation strategies as defined by Gross (1998) as second-order factors (i.e. situation selection, situation modification, attentional deployment, cognitive change, response modulation, emotion expression) and nineteen first-order dimensions (the same as for model 
2 and model 3) (see Figure 1).

Table 5 shows the goodness-of-fit statistics for the four models. Model 1 is the only one that displays fit indices of acceptable range indicating that the model fitted the data well. This finding supports the exploratory factor structure.

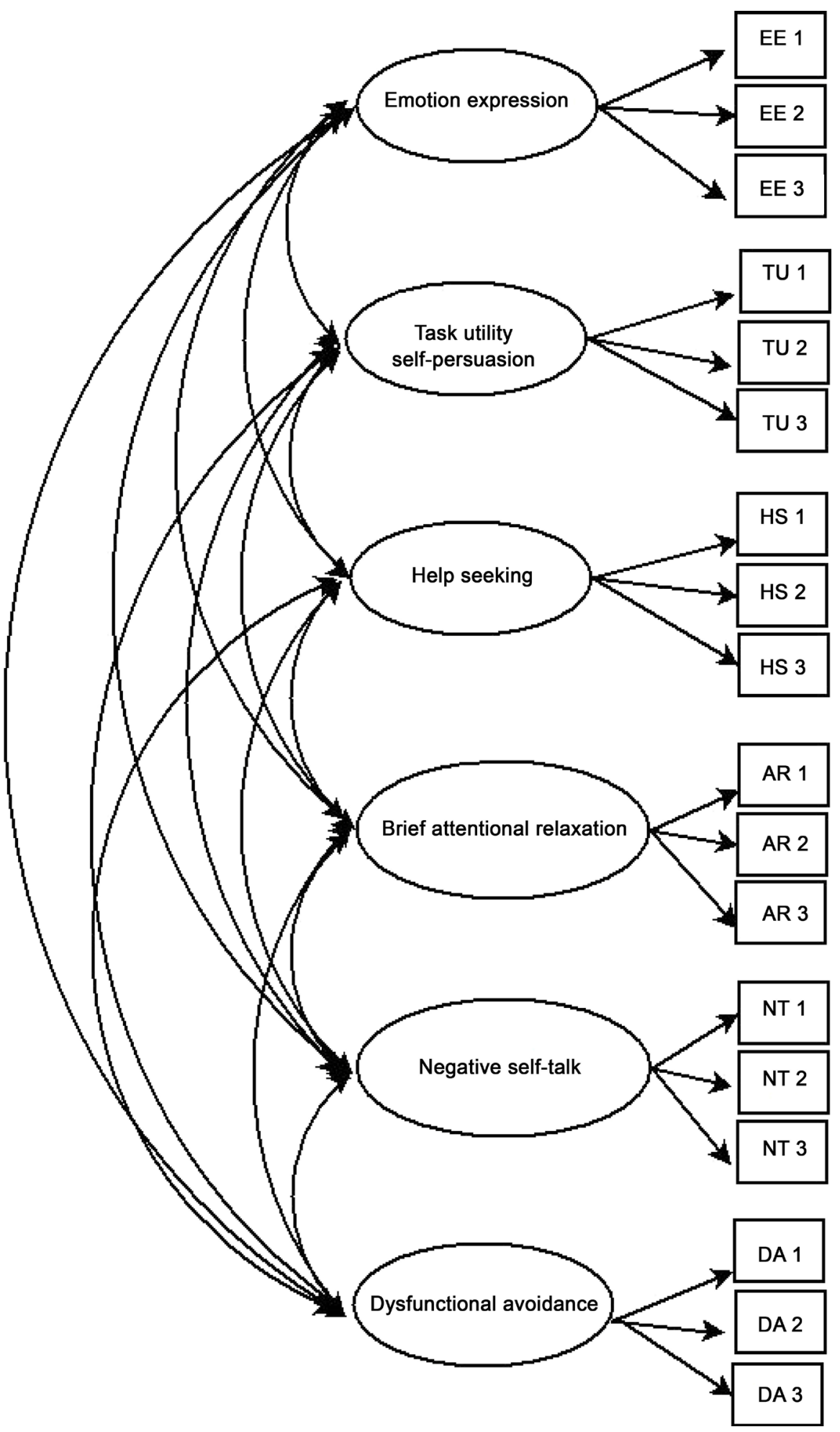

Model 1 


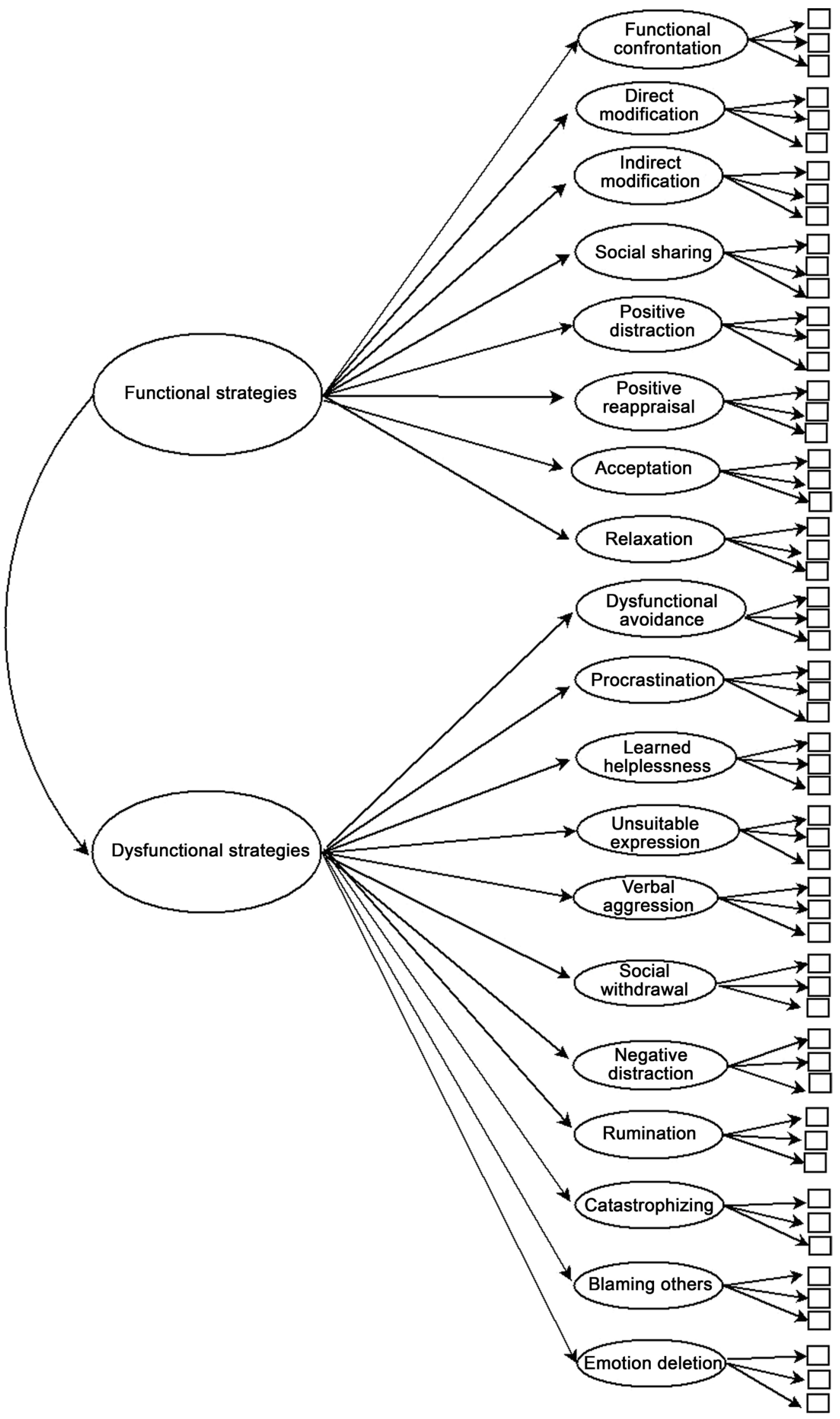

Model 2 


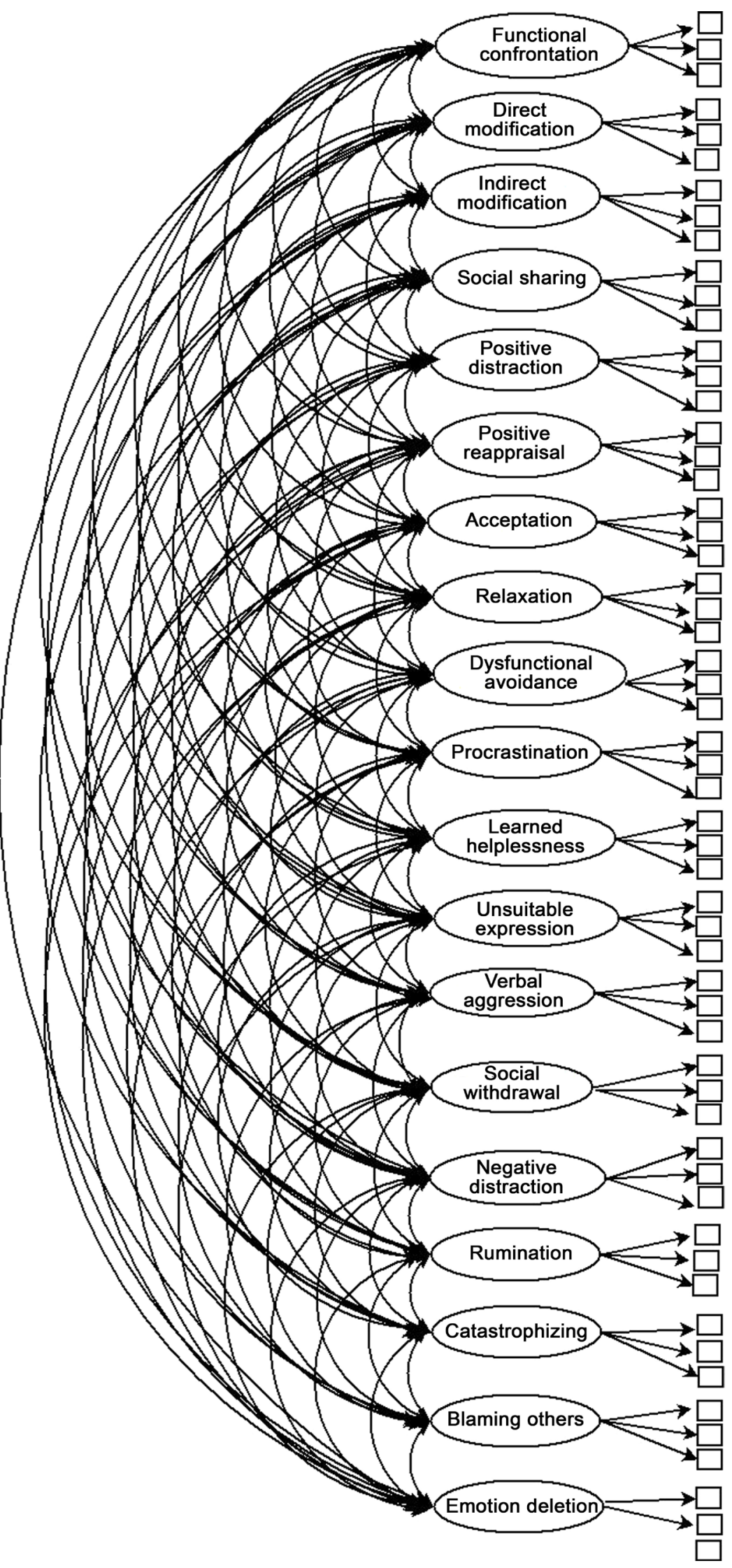

Model 3 


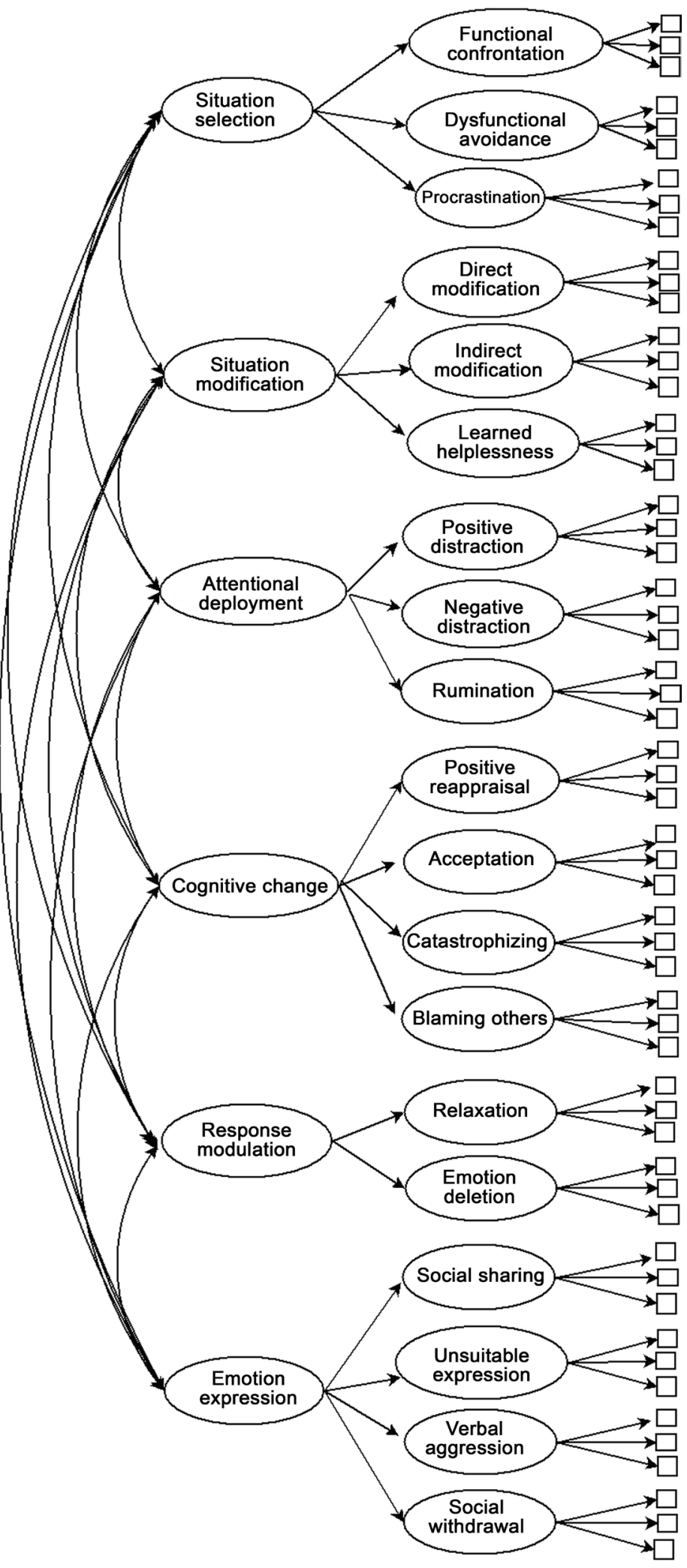

Model 4

Figure 1. Model for component structures of emotion regulation strategies. Model 1 (six first-order factors). Model 2 (two second-order factors). Model 3 (nineteen first-order factors). Model 4 (six second-order factors). 
Table 5. Summary of goodness-of-fit statistics for confirmatory factor analysis.

\begin{tabular}{cccccccc}
\hline Model & $\chi^{2}$ & $\mathrm{df}$ & $\chi^{2} / \mathrm{df}$ & RMSEA & SRMR & CFI & AGFI \\
\hline Model 1 & 595.747 & 308 & 1.934 & 0.046 & 0.052 & 0.940 & 0.927 \\
Model 2 & 4049.375 & 1519 & 1.144 & 0.054 & 0.077 & 0.723 & 0.749 \\
Model 3 & 2971.821 & 1372 & 2.166 & 0.045 & 0.082 & 0.825 & 0.812 \\
Model 4 & 4138.043 & 1507 & 2.746 & 0.055 & 0.153 & 0.712 & 0.756 \\
\hline
\end{tabular}

Note. $\mathrm{N}=568 ; \chi^{2}=$ chi-square; $\mathrm{df}=$ degrees of freedom; $\chi^{2} / \mathrm{df}=$ ratios of the chi-square to its degrees of freedom; RMSEA = Root Mean Square Error of Approximation; SRMR = Standardized Root Mean Square Residual; CFI = Comparative Fit Index; AGFI = Adjusted Goodness of Fit Index.

\subsection{Discussion}

In the present section the main findings regarding both the psychometrical properties of the CERS-M and the emotion regulation behavior of fifth and sixth graders are discussed.

First, both exploratory and confirmatory factor analyses have shown that neither the bipolar structure (i.e. functional and dysfunctional strategies) nor the theoretical 19 factor structure were suited for upper elementary students. Rather, it follows from this first study that the model that best fit the data encompasses six factors, i.e. emotion expression, task utility self-persuasion, negative self-talk, help seeking, brief attentional relaxation, and dysfunctional avoidance. Although this finding is at odds with our theoretical expectations, it is congruent with previous empirical studies which have shown that both students and adults are not able to discriminate among all strategies theoretically defined (De Corte et al., 2011; Nelis et al., 2011). In that respect, in their study, conducted with students aged between 14 and 16, De Corte et al. (2011) were not able to replicate the original structure of the COPE questionnaire (15 subscales) but instead identified six reliable factors. In addition, these results confirm that scales designed for (young) adults are not suited, as they stand, for children and teenagers.

Second, the six dimensions resulting from this first study address all the components of the emotion generative process suggested by Gross (1998). In this connection, "task utility self-persuasion" addresses two components of this process, that is, situation selection, by deciding to launch into the problem despite the fact that it generates unpleasant emotions and cognitive change by convincing oneself of the utility of the task. With regard to "help seeking", it aims to get rid of unpleasant emotions by asking someone's help and thereby modifies the situation. Regarding "brief attentional relaxation", it can be used either to modify one's attentional focus or to modulate the bodily component of the emotion through relaxing behaviors. "Dysfunctional avoidance", insofar as it consists in avoiding mathematical tasks as a source of negative emotions but that are associated to long-term benefits, is associated with the situation selection component. "Negative self-talk" addresses three components of the emotion generative process: situation modification, by convincing oneself that the situation is hopeless; attentional deployment, by dwelling on negative thoughts and emotions; 
and cognitive change, by catastrophizing the situation. Finally, as one might expect, "emotion expression" addresses the emotion expression component. This suggests that fifth and sixth graders have strategies, at least one of them functional, that allow them to control their emotions at each step of the process of emotion generation. Thus, an instrument whose ambition is to measure the strategies used by $5^{\text {th }}$ and $6^{\text {th }}$ graders to regulate the negative emotions emerging during problem-solving tasks has to cover all the components involved in the emotion generative process. In this respect, both the CERQ-child and the Flemish version COPE-questionnaire appear to be incomplete instruments (see Appendix A).

Third, functional strategies appeared to be more often used than dysfunctional strategies by $5^{\text {th }}$ and $6^{\text {th }}$ graders in the context of math problem solving. This is good news. However, for both kinds of strategies this use remains limited, which is congruent with previous findings showing that students have a poor track record of emotion regulation during problem-solving tasks (De Corte et al., 2011). Further, the factor pattern matrix shows that social sharing loads with the same valence on the same factor as two dysfunctional strategies, namely, unsuitable expression and verbal aggression. This suggests that expressing one's emotions during problem-solving tasks is considered inappropriate by upper elementary students. In addition, it turned out that the most-used strategy (task utility self-persuasion) is centered on the task while most of the least-used strategies focused on the emotion(s) felt (i.e. emotion expression, negative self-talk, dysfunctional avoidance). These last two observations align closely with those of several scholars (Desmarets, Jadin, Rouche, \& Sartiaux, 1997; Pallascio \& Lafortune, 2000) according to which mathematics is viewed as a "cold" discipline where emotions do not belong.

\section{Study 2}

This second study aims at providing additional evidence of the validity and reliability of the CERS-M by examining the differential, convergent, discriminant and criterion validity of the instrument as well as its test-retest reliability (Laveault \& Grégoire, 2014).

\subsection{Method}

\subsubsection{Participants and Procedure}

Data collection took place from October 2015 until December 2015. The 19-items instrument was administered to $1014^{4}$ fifth and sixth graders (502 girls, mean age: $10.7 \pm 0.66$ years) drawn from 20 elementary schools. The latter are located in five out of the six French-speaking geographical areas. In doing so, our sample tends to be as representative as possible of the population of interest. It is also worth noting that 43 additional students were involved in a pilot study whose objective was to ensure the clarity and understanding of all question-

${ }^{4}$ We opted for the suppression of missing data. 
naires. In addition, students filled in the CERS-M during a mathematical class, along with several other measures (during separate sessions). As for study 1, all items were read aloud by the teacher. In case of misunderstanding, the problematic words or sentences were rephrased by the teacher. In addition, in order to document the test-retest reliability and the predictive validity, several measures were taken twice at an interval of three months.

\subsubsection{Measures}

Emotion Regulation was appraised through the CERS-M described in study 1 (Items available in Appendix B) and through a French version of the Flemish COPE-questionnaire also presented in study 1 . This translation was made by a bilingual Flemish native speaker. Except for active coping $(\alpha=0.51)$, and restraint coping ( $\alpha=0.37$ ), the subscales of the COPE-questionnaire showed satisfactory internal consistency in our sample, with Cronbach's alphas ranging from 0.62 to 0.88 .

Verbal skill was assessed by means of the syntactico-semantic test "E.C.O.S.S.E", designed by Lecocq (1996). In this study, this test appraises the comprehension of 25 oral statements. The subject had to choose from four pictures the one that was the exact illustration of the sentence just read by the teacher.

Global mathematics anxiety was appraised using an adapted version of the Abbreviated Math Anxiety Scale (AMAS) of Hopko, Mahadevan, Bare and Hunt (2003). For ten school-related mathematics activities (i.e., solving a math problem alone, doing a math exercise alone, thinking about the math test tomorrow, watching the teacher solving a math problem on the board, answering a math exam, dealing with a difficult math homework, listening to the math lesson, listening to another student explaining a math exercise, getting a surprise math test, and starting a new math chapter), the respondent was asked to indicate his level of anxiety using a 5 -point Likert scale $(1=$ null to $5=$ very high $)$. This information was collected at two points. The internal consistency of the scale was excellent (Time 1: $\alpha=0.89$, Time 2: $\alpha=0.89$ ).

Math test anxiety was evaluated via a translated version of the revised version of the "Children's Test Anxiety Scale (CTAS)" (Nyroos, Korhonen, Linnanmaki, \& Svens-Liavag, 2012). This instrument assesses the individual's level of anxiety about testing. It includes three dimensions: thoughts (11 items, e.g., "I think I'm going to get a bad grade"); autonomic reactions ( 3 items, e.g., "During a math test, I feel warm"), and off-task behaviors (5 items, e.g., "During a math test, I look around me"). Participants indicated the frequency of each of these thoughts, autonomic reactions, and off-task behaviors using a 4-point Likert scale $(1=$ (almost) never to $4=($ almost $)$ always). Again, this information was collected at two points. The internal consistency of the global score of anxiety in our sample was excellent (Time 1: $\alpha=0.90$, Time 2: $\alpha=0.91$ ).

Problem-solving anxiety was measured by transforming the CTAS into an anxiety problem-solving scale. Concretely, the term "math test" was replaced by "problem solving". Apart from this change, the rest remained unchanged. The 
internal consistency of the global score of problem-solving anxiety was excellent too (Time 1: $\alpha=0.92$, Time 2: $\alpha=0.92$ ).

Problem-solving performances were assessed by means of a performance test made up of three problems. These were designed on the basis of our expertise as mathematics teachers and on one textbook, "To solve problems: no problem!" written by Fagnant and Demonty (2005). Student performance was appraised by a global score obtained by summing up the correct answers on a binary scale ( 0 = wrong answer, 1 = right answer).

Global performances were collected from teachers in June 2015 and in December 2015 for Mathematics, and only in December 2015 for French. This information allows us to control for previous math performance and simultaneous French performance.

\subsection{Results}

\subsubsection{Evidence of the CERS-M's Reliability}

The internal consistency of four subscales, namely, emotion expression, task utility self-persuasion, help seeking, and dysfunctional avoidance was substantially improved with the removal of one item. This choice was confirmed by correlational analysis on every trio of items. As shown in Table 6, the internal consistency of the CERS-M's subscales is of acceptable range. It is also worth noting the presence of a substantial increase of the value of the Cronbach's alphas between the two times of measure.

With respect to the test-retest reliability, the score after three months is good (Pearson's $r=0.63, p<0.01$ ) which indicates a satisfactory stability of the CERS-M global score over time. The stability of the CERS-M's subscales is satisfactory to good (Pearson's $r$ ranging between 0.39 and 0.63 ).

\subsubsection{Evidences of the CERS-M's Construct Validity}

Goodness-of-fit indices for the six-factor model with 14 items indicate a welladjusted fit to the data $\left(\chi^{2} / \mathrm{df}=1.427, \mathrm{RMSEA}=0.019, \mathrm{SRMR}=0.021, \mathrm{CFI}=\right.$ 0.992 , AGFI $=0.982)$ which confirms study l's findings. In addition, the six-factor

Table 6. Internal consistencies for the six subscales of the CERS-M.

\begin{tabular}{ccc}
\hline \multirow{2}{*}{ Factors } & \multicolumn{2}{c}{ Cronbach's Alpha } \\
\cline { 2 - 3 } & Time 1 & Time 2 \\
\hline CERS-M Global score (14 items) & 0.70 & 0.76 \\
Emotion expression (2 items) & 0.66 & 0.75 \\
Task utility self-persuasion (2 items) & 0.67 & 0.74 \\
Negative self-talk (3 items) & 0.76 & 0.84 \\
Help seeking (2 items) & 0.77 & 0.83 \\
Brief attentional relaxation (3 items) & 0.65 & 0.76 \\
Dysfunctional avoidance (2 items) & 0.62 & 0.66
\end{tabular}

Note. $\mathrm{N}=1014$; Time 1 = October 2015; Time 2 = December 215. 
model appears to better fit the data than an alternative model made up of two second-order factors (functional strategies and dysfunctional strategies) and of six first-order factors (emotion expression, task utility self-persuasion, negative self-talk, help seeking, brief attentional relaxation, and dysfunctional avoidance) $\left(\chi^{2} / \mathrm{df}=1.860, \mathrm{RMSEA}=0.027, \mathrm{SRMR}=0.033, \mathrm{CFI}=0.981, \mathrm{AGFI}=0.977\right)$.

\subsubsection{Evidence of the CERS-M's Differential Validity}

Let us start by remembering that when differential validity is addressed, "it is the lack of observed difference that should be problematic and question the quality of a test and not the opposite" (Laveault \& Grégoire, 2014, free translation, p. 93). In fact, the presence of a significant difference between the two groups reflects the ability of the test to take into account reality. As depicted in Table 7, there is a significant gender difference in the use of emotion regulation strategies. This difference concerns, more specifically, four emotion regulation strategies, namely, emotion expression, task utility self-persuasion, negative self-talk, and help seeking. Even so, whether it is a functional or a dysfunctional strategy, girls score higher than boys, supporting the idea that emotions are more a concern of girls than of boys (Brody, 2000).

\subsubsection{Evidence of the CERS-M's Discriminant Validity}

Discriminant validity refers to the degree to which scores on a test do not correlate with variables they are not supposed to correlate with given the nature of the concept (Laveault \& Grégoire, 2014; Messick, 1995). It was assessed by examining Pearson correlations between CERS-M and verbal skills. Table 8 shows that the relationship between the CERS-M global score and verbal skills is very tenuous $(r=-0.09)$. Furthermore, this relationship concerns only two subscales out of the six, that is, negative self-talk, and dysfunctional avoidance. Such findings are not surprising as these two emotion regulation strategies are known to redirect, partially or totally, the individual's cognitive resources, initially available for the task, to his/her emotions and thoughts (negative self-talk) or on another task (dysfunctional avoidance).

Table 7. Means, standard deviations and t-test comparisons for boys and girls.

\begin{tabular}{cccccc}
\hline \multirow{2}{*}{ Subscales } & \multicolumn{2}{c}{ Boys $(\mathrm{N}=512)$} & Girls $(\mathrm{N}=502)$ & Gender differences \\
\cline { 2 - 6 } & $\mathrm{M}$ & $\mathrm{SD}$ & $\mathrm{M}$ & $\mathrm{SD}$ & t-test \\
\hline CERS-M global score & 1.95 & 0.40 & 2.10 & 0.41 & $t(1015)=-5.83^{* * * *}$ \\
Emotion expression & 1.44 & 0.58 & 1.52 & 0.57 & $t(1015)=-2.06^{*}$ \\
Task utility self-persuasion & 2.86 & 0.93 & 3.00 & 0.80 & $t(1015)=-2.52^{*}$ \\
Negative self-talk & 1.58 & 0.69 & 1.91 & 0.84 & $t(1015)=-6.69^{* * *}$ \\
Help seeking & 2.16 & 0.72 & 2.32 & 0.76 & $t(1015)=-3.56^{* * *}$ \\
Brief attentional relaxation & 2.08 & 0.74 & 2.14 & 0.73 & $t(1015)=-1.38$ \\
Dysfunctional avoidance & 1.69 & 0.76 & 1.76 & 0.76 & $t(1015)=-1.59$ \\
\hline
\end{tabular}

Note. $\mathrm{N}=$ Sample size; $\mathrm{M}=$ mean; $\mathrm{SD}=$ standard deviation. ${ }^{* * *} p \leq 0.001 ;{ }^{* *} p \leq 0.01 ;{ }^{*} p \leq 0.05$. 


\subsubsection{Evidence of the CERS-M's Convergent Validity}

Convergent validity pertains to the degree to which scores on a test are closely related to measures of a similar construct (Laveault \& Grégoire, 2014; Messick, 1995). It was appraised by examining Pearson correlations between the CERS-M and another measure of emotion regulation, namely, the Flemish version of the COPE-questionnaire (De Corte et al., 2011). As shown in Table 8, the CERS-M global score is strongly associated with the COPE global score $(r=0.52)$. As can be seen from Table 8, this association is mostly attributable to five dimensions of the COPE, i.e., seeking social support for emotional reasons, seeking social support for instrumental reasons, focus on and venting emotions, mental disengagement and behavioral disengagement, those who present relevant conceptual overlaps with the CERS-M subscales.

\subsubsection{Evidence of the CERS-M's Criterion Validity}

Criterion validity refers to the extent to which an instrument is associated with or predicts a given concept or an external criterion (Bryant, 2000). When the two measures are collected concurrently we speak about concomitant validity whereas when a temporal delay separates the two measures we talk about predictive validity. In the present study, criterion validity has been examined in the light of two criteria, anxiety and performance.

CERS-M and Anxiety. Not surprisingly, scholars have highlighted a close relationship between emotion regulation and anxiety (Amstadter, 2008; Gross \& Munoz, 1995; Mikolajczak, Luminet, Leroy, \& Roy, 2007; Nelis et al., 2011). More precisely, individuals who cannot regulate their emotions experience more anxiety than those who display emotion regulation skills. In other words, functional strategies are supposed to correlate negatively with anxiety whereas dysfunctional strategies are supposed to correlate positively with it. Regarding concomitant validity, findings revealed a positive relationship between CERS-M global score and indicators of anxiety (Table 8). Among the different measures of anxiety, the strongest correlations are observed for math test anxiety and problem- solving anxiety. This finding is congruent with the conceptualization of emotions as task-related objects (Goetz et al., 2007; Goetz et al., 2006). In addition, these strong correlations concern only one emotion regulation strategy, namely, "negative self-talk". Thus, these findings indicate, on the one hand, that emotion regulation as assessed by the CERS-M and math task anxiety are two distinct constructs, and, on the other hand, that one of the CERS-M's subscales, i.e. negative self-talk, shares with math tasks anxiety between $27 \%$ and $31 \%$ of the common variance. With respect to predictive validity, regressions sought to examine whether the CERS-M is able to predict indicators of anxiety, measured three months later and in doing so, to complement the concomitant validity analysis. As depicted in Table 9, CERS-M global score is a significant predictor of anxiety. Again, the predictions are more powerful when measures of anxiety are related to well-defined mathematical tasks (i.e., a test or a problem to solve). Congruent with the correlational analyses, negative self-talk is the CERS-M 
Table 8. Correlations of the CERS-M subscales and indicators of discriminant, convergent and concomitant validity.

\begin{tabular}{|c|c|c|c|c|c|c|c|}
\hline & $\begin{array}{c}\text { CERS-M } \\
\text { Global score }\end{array}$ & $\begin{array}{l}\text { Emotion } \\
\text { expression }\end{array}$ & $\begin{array}{c}\text { Task utility } \\
\text { self-persuasion }\end{array}$ & $\begin{array}{l}\text { Negative } \\
\text { self-talk }\end{array}$ & $\begin{array}{l}\text { Help } \\
\text { seeking }\end{array}$ & $\begin{array}{l}\text { Brief attentional } \\
\text { relaxation }\end{array}$ & $\begin{array}{c}\text { Dysfunctional } \\
\text { avoidance }\end{array}$ \\
\hline \multicolumn{8}{|l|}{ Discriminant validity } \\
\hline E.C.O.S.S.E. Global score & $-0.094^{\star *}$ & -0.044 & 0.026 & $-0.137^{\star *}$ & -0.049 & 0.001 & $-0.091^{\star *}$ \\
\hline \multicolumn{8}{|l|}{ Convergent validity } \\
\hline COPE Global score & $0.519^{* *}$ & $0.326^{* *}$ & $0.261^{* *}$ & $0.303^{* *}$ & $0.275^{\star *}$ & $0.289^{* *}$ & $0.250^{* *}$ \\
\hline Planning & $0.107^{* *}$ & -0.032 & $0.301^{* *}$ & $-0.078^{*}$ & $0.139^{* *}$ & 0.025 & 0.030 \\
\hline Suppression of competing activities & 0.059 & $-0.099^{\star *}$ & $0.329^{* *}$ & -0.037 & $0.104^{\star *}$ & -0.044 & -0.060 \\
\hline Seeking social support for emotional reasons & $0.415^{\star \star}$ & $0.302^{* *}$ & $0.149^{* *}$ & $0.266^{* *}$ & $0.228^{* *}$ & $0.211^{\star *}$ & $0.219^{* *}$ \\
\hline Seeking social support for instrumental reasons & $0.422^{* *}$ & $0.296^{* *}$ & $0.109^{* *}$ & $0.224^{\star *}$ & $0.286^{* *}$ & $0.270^{* *}$ & $0.219^{* *}$ \\
\hline Positive reinterpretation and growth & $0.235^{* *}$ & $0.097^{\star *}$ & $0.301^{* *}$ & 0.053 & $0.145^{\star *}$ & $0.125^{\star *}$ & 0.060 \\
\hline Acceptance & $0.238^{\star *}$ & $0.144^{* *}$ & $0.187^{\star *}$ & $0.130^{* *}$ & $0.076^{*}$ & $0.116^{* *}$ & $0.128^{\star *}$ \\
\hline Turning to religion & $0.172^{* *}$ & $0.099^{* *}$ & $0.109^{* *}$ & $0.143^{\star *}$ & $0.146^{* *}$ & 0.027 & 0.043 \\
\hline Focus on and venting emotions & $0.420^{* *}$ & $0.322^{* *}$ & 0.055 & $0.354^{\star *}$ & $0.163^{* *}$ & $0.211^{* *}$ & $0.262^{* *}$ \\
\hline Denial & $0.277^{\star \star}$ & $0.188^{\star *}$ & $0.066^{*}$ & $0.230^{\star *}$ & $0.094^{\star *}$ & $0.162^{\star \star}$ & $0.141^{\star \star}$ \\
\hline Behavioral disengagement & $0.348^{* *}$ & $0.285^{* *}$ & $-0.106^{* *}$ & $0.379^{\star *}$ & $0.113^{* *}$ & $0.206^{* *}$ & $0.217^{\star *}$ \\
\hline Mental disengagement & $0.422^{* *}$ & $0.303^{* *}$ & 0.005 & $0.269^{* *}$ & $0.134^{\star *}$ & $0.363^{* *}$ & $0.274^{* *}$ \\
\hline Joking & $0.178^{* *}$ & $0.206^{* *}$ & 0.032 & 0.025 & $0.062^{\star}$ & $0.202^{\star *}$ & $0.084^{* *}$ \\
\hline \multicolumn{8}{|l|}{ Concomitant validity } \\
\hline Global math anxiety & $0.357^{\star *}$ & $0.216^{* *}$ & $0.067^{*}$ & $0.400^{\star *}$ & $0.163^{* *}$ & $0.098^{* *}$ & $0.180^{* *}$ \\
\hline Math test anxiety & $0.559^{* *}$ & $0.347^{* *}$ & 0.051 & $0.560^{\star *}$ & $0.212^{* *}$ & $0.310^{* *}$ & $0.252^{* *}$ \\
\hline Problem-solving anxiety & $0.477^{\star *}$ & $0.296^{\star *}$ & 0.030 & $0.521^{\star *}$ & $0.152^{\star *}$ & $0.238^{\star *}$ & $0.229^{* *}$ \\
\hline Problem-solving performance & $-0.180^{* *}$ & $-0.075^{\star *}$ & 0.043 & $-0.210^{\star *}$ & $-0.097^{\star *}$ & -0.022 & $-0.119^{* *}$ \\
\hline
\end{tabular}

Note. $\mathrm{N}=1014$. ${ }^{* * *} p \leq 0.001 ;{ }^{* *} p \leq 0.01 ;{ }^{*} p \leq 0.05$.

Table 9. Hierarchical regression analyses predicting anxiety and problem-solving performance by the CERS-M.

\begin{tabular}{|c|c|c|c|c|c|c|c|c|}
\hline \multirow{2}{*}{$\begin{array}{l}\text { Dependent variable } \\
\text { Predictor variables }\end{array}$} & \multicolumn{2}{|c|}{ Global math anxiety } & \multicolumn{2}{|c|}{ Math test anxiety } & \multicolumn{2}{|c|}{ Problem-solving anxiety } & \multicolumn{2}{|c|}{ Problem-solving performance } \\
\hline & Adjusted $\mathrm{R}^{2}$ & Bêta & Adjusted $\mathrm{R}^{2}$ & Bêta & Adjusted $\mathrm{R}^{2}$ & Bêta & Adjusted $\mathrm{R}^{2}$ & Bêta \\
\hline CERS-M global score & 0.12 & $0.35^{* * *}$ & 0.25 & $0.50^{* * *}$ & 0.22 & $0.47^{\star * *}$ & 0.016 & $-0.13^{* * *}$ \\
\hline Emotion expression & 0.04 & $0.20^{* * *}$ & 0.08 & $0.28^{* * *}$ & 0.07 & $0.26^{* * *}$ & 0.001 & -0.044 \\
\hline Task utility self-persuasion & 0.005 & $0.07^{\star *}$ & 0.00 & 0.02 & 0.001 & 0.05 & -0.001 & -0.012 \\
\hline Negative self-talk & 0.16 & $0.41^{\star * *}$ & 0.26 & $0.51^{\star * *}$ & 0.26 & $0.51^{\star * *}$ & 0.04 & $-0.20^{* * *}$ \\
\hline Help seeking & 0.02 & $0.16^{* * *}$ & 0.03 & $0.19^{\star * *}$ & 0.03 & $0.17^{* * *}$ & 0.004 & $-0.07^{\star}$ \\
\hline Brief attentional relaxation & 0.004 & $0.07^{*}$ & 0.07 & $0.27^{\star * *}$ & 0.05 & $0.22^{\star * *}$ & -0.001 & 0.013 \\
\hline Dysfunctional avoidance & 0.04 & $0.21^{\star * *}$ & 0.08 & $0.28^{\star * *}$ & 0.06 & $0.25^{\star * *}$ & 0.008 & $-0.09^{\star * \star}$ \\
\hline
\end{tabular}

Note. $\mathrm{N}=1014 .{ }^{* * *} p \leq 0.001 ; ;^{* *} p \leq 0.01 ; ;^{*} p \leq 0.05$. 
subscale that best predicts math tasks anxiety (Adjusted $\mathrm{R}^{2}=26 \%$ ).

$C E R S-M$ and math performance. Findings are ambivalent as far as the effects of emotion regulation on academic performance are concerned. While several researchers have put forward tenuous correlations or no correlation at all (Jordan, McRorie, \& Ewing, 2010; Mavroveli, Petrides, Shove, \& Whitehead, 2008; Petrides Frederickson, \& Furnham, 2004), others have emphasized the predictive power of emotion regulation for academic achievement (Di Fabio \& Palazzeschi, 2009; Van der Zee, Tijs, \& Schakel, 2002). Regarding concomitant validity, as shown in Table 8 , the relation between CERS-M global score and problem- solving performance is negative and tenuous $(\mathrm{r}=-0.18)$ indicating that there are clearly two distinct constructs that have little in common. This finding is strengthened by the analysis of the predictive validity, which highlights that the CERS-M accounts for less than $2 \%$ of problem-solving performance variance (Table 9). Negative self-talk appeared to be the strongest predictor of problem-solving performance, accounting for $4 \%$ of the total variance. Additionally, we examined if the CERS-M global score was a significant predictor of global math performance (measured three months after the administration of the CERS-M), when controlling for both French performance (measured three months after the administration of the CERS-M) and previous math performance (measured three months before the administration of the CERS-M). Hierarchical regression analyses using the "Enter" procedure were therefore computed. In line with our findings regarding problem-solving performance, the CERS-M contributes marginally $\left(R^{2}=2 \%\right)$ in the prediction of global math performance, mainly through negative self-talk $\left(R^{2}=2 \%\right)$ and emotion expression $\left(R^{2}=1.8 \%\right.$ (see Table 10$)$.

The CERS-M and the COPE-questionnaire. Additional evidence of the CERS-M's criterion validity consists in examining its ability to account for additional variance in the prediction of anxiety and problem-solving performance, over and above the COPE scores (e.g., MacCann, Roberts, Matthews, \& Zeidner, 2004; Schulte, Ree, \& Carretta, 2004). It should be remembered that the COPEquestionnaire appraises emotion regulation too. To answer this question we performed hierarchical regression analyses. More precisely, scores from the COPE were entered as the first block, and scores from the CERS-M were entered as the second block. The analysis was computed twice, the first time with anxiety as dependent variable and, the second time, with problem-solving performance as dependent variable. Regarding indicators of anxiety, as depicted in Table 11, the CERS-M significantly predicted global math anxiety, math test anxiety and problem-solving anxiety over and above the COPE-questionnaire. Again, the prediction power is higher both in the math test $\left(\mathrm{R}^{2}=16 \%\right)$ and in the problemsolving $(12 \%)$ condition than in the global math context $\left(\mathrm{R}^{2}=6 \%\right)$. With respect to problem-solving performance, Table 11 shows that this is also significantly predicted, but to a lesser extent $\left(\mathrm{R}^{2}=2 \%\right)$, by the CERS-M scores over and above the effects of COPE scores. 
Table 10. Hierarchical regression analyses predicting global math performance, measured three months later, over and above French performance and previous math performance, by the CERS-M.

\begin{tabular}{|c|c|c|c|c|c|}
\hline Criterion variable & Forced hierarchical order & Predictor variable & $\mathrm{R}$ & Adjusted $\mathrm{R}^{2}$ change & F change \\
\hline \multirow[t]{2}{*}{ Math performance } & 1 & $\begin{array}{l}\text { Previous math performance } \\
\text { French performance }\end{array}$ & 0.265 & 0.068 & $37.308^{* * *}$ \\
\hline & 2 & CERS-M scores & 0.303 & 0.021 & $23.036^{* * *}$ \\
\hline \multirow[t]{2}{*}{ Math performance } & 1 & $\begin{array}{l}\text { Previous math performance } \\
\text { French performance }\end{array}$ & 0.079 & 0.004 & $3.136^{*}$ \\
\hline & 2 & Emotion expression & 0.158 & 0.018 & $18.904^{* * *}$ \\
\hline \multirow[t]{2}{*}{ Math performance } & 1 & $\begin{array}{l}\text { Previous math performance } \\
\text { French performance }\end{array}$ & 0.067 & 0.002 & 2.206 \\
\hline & 2 & Task utility self-persuasion & 0.073 & 0.00 & 0.900 \\
\hline \multirow[t]{2}{*}{ Math performance } & 1 & $\begin{array}{l}\text { Previous math performance } \\
\text { French performance }\end{array}$ & 0.296 & 0.086 & $47.322^{* * *}$ \\
\hline & 2 & Negative self-talk & 0.330 & 0.02 & $23.910^{\star * *}$ \\
\hline \multirow[t]{2}{*}{ Math performance } & 1 & $\begin{array}{l}\text { Previous math performance } \\
\text { French performance }\end{array}$ & 0.150 & 0.021 & $11.412^{* * *}$ \\
\hline & 2 & Help seeking & 0.162 & 0.002 & 3.546 \\
\hline \multirow[t]{2}{*}{ Math performance } & 1 & $\begin{array}{l}\text { Previous math performance } \\
\text { French performance }\end{array}$ & 0.104 & 0.009 & $5.349^{* *}$ \\
\hline & 2 & Brief attentional relaxation & 0.145 & 0.009 & $10.398^{* * *}$ \\
\hline \multirow[t]{2}{*}{ Math performance } & 1 & $\begin{array}{l}\text { Previous math performance } \\
\text { French performance }\end{array}$ & 0.159 & 0.023 & $12.754^{* * *}$ \\
\hline & 2 & Dysfunctional avoidance & 0.165 & 0.001 & 2.076 \\
\hline
\end{tabular}

Note. $\mathrm{N}=1014$. Adjusted $\mathrm{R}^{2}$ change $=$ change in $\mathrm{R}^{2}$ resulting from the inclusion of a new predictor. ${ }^{* * *} p \leq 0.001 ; * * 0.01 ; p \leq 0.05$.

Table 11. Hierarchical regression analyses testing the criterion validity of the CERS-M over and above COPE's scores to predict global math anxiety.

\begin{tabular}{cccccc}
\hline Criterion variable & Forced hierarchical order & Predictor variable & R & Adjusted $\mathrm{R}^{2}$ change & F change \\
\hline Global math anxiety & 1 & COPE total score & 0.282 & 0.078 & $87.35^{* * *}$ \\
& 2 & CERS-M total score & 0.379 & 0.064 & $76.054^{* * *}$ \\
Math test anxiety & 1 & COPE total score & 0.426 & 0.181 & $224.85^{* * *}$ \\
Problem-solving anxiety & 2 & CERS-M total score & 0.583 & 0.157 & $242.98^{* * *}$ \\
& 1 & COPE total score & 0.366 & 0.133 & $156.95^{* * *}$ \\
Problem-solving performance & 2 & CERS-M total score & 0.500 & 0.116 & $157.26^{* * *}$ \\
& 1 & COPE total score & 0.092 & 0.008 & $9.83^{* *}$ \\
\hline
\end{tabular}

Note. $\mathrm{N}=1014$. Adjusted $\mathrm{R}^{2}$ change $=$ change in $\mathrm{R}^{2}$ resulting from the inclusion of a new predictor. ${ }^{* * *} p \leq 0.001 ;{ }^{* *} p \leq 0.01 ;{ }^{*} p \leq 0.05$.

\subsection{Discussion}

The second study pursued a twofold objective. A first objective consisted in confronting the factor structure of the CERS-M, resulting from the first study, with 
another sample, and by doing so, to consolidate the construct validity of the instrument. In this connection, the second study globally confirmed that the sixfactor model presents a good adjustment to the data.

A second objective was to question the validity and reliability of the CERS-M from different perspectives in order to provide additional evidence of the psychometrical properties of the scale. On this point, and although collecting evidence of the validity of an instrument is a process always in progress (Laveault \& Grégoire, 2014), this study provided differential, discriminant, convergent and criterion preliminary evidence of the CERS-M's validity. With respect to the discriminant validity, unexpectedly, our findings stressed a tenuous relationship between two subscales of the CERS-M, namely, negative self-talk and dysfunctional avoidance, and verbal skills. It is probably not insignificant that it is the same two strategies that correlate most strongly with students' problem-solving performance. If these two strategies particularly affect performance scores, it may be because these strategies prevent the individual from doing the task. Thus, the theory according to which individual differences in typical behavior in emotional situations are independent of cognitive intelligence is only partially corroborated (Freudenthaler \& Neubauer, 2005, 2007). With respect to convergent validity, a significant and strong relation was found between the global score of the COPE and the CERS-M. A fine-grained analysis revealed that it is five dimensions in particular of the COPE that are concerned. This finding may be explained by the presence of conceptual overlaps between the two instruments. However, the CERS-M cannot be reduced to the five overlapping constructs of the COPE for two main reasons. First, the intensity of the correlations of these five constructs is only moderate. Second, the CERS-M appeared to predict measures of anxiety as well as problem-solving performance over and above COPE scores. This evidence of criterion validity points out that scales measuring close constructs, such as the COPE, cannot do the job, at least not as efficiently as the CERS-M. With regard to the CERS-M reliability, if the test-retest reliability suggests that emotion regulation strategies are relatively stable constructs the internal consistency of the CERS-M subscales indicates that the instrument would benefit from improving the reliability of one of its subscales, namely, dysfunctional avoidance.

In addition, from the standpoint of gaining a better understanding of emotion regulation, two findings deserve to be analyzed more thoroughly.

A first interesting result concerns gender difference. On this point, it is useful to recall that four emotion regulation strategies stood out as being more used by girls than by boys, namely, emotion expression, negative self-talk, help seeking, and task utility self-persuasion. Findings regarding the first three strategies are coherent with Western norms according to which girls are more likely to express their emotions and to use internalization strategies to cope with emotionally loaded situations than are boys (Brody, 2000). It is also congruent with findings showing that girls score lower on alexithymia than boys (Joukamaa, Taanila, 
Miettunen, Karvonen et al., 2007; Levant, Hall, Williams, \& Hasan, 2009). This difference between genders could also be explained by the stereotype threat (i.e. girls have weaker math ability than boys) (Ambady, Shih, Kim, \& Pittinsky, 2001). The apprehension caused by this threat may disrupt girls' problem-solving performance and, in doing so, entail the use of emotional expression, negative self-talk, and help seeking. Furthermore, the greater need for girls than for boys to convince themselves of the utility of the task to be engaged in it was already noted by Eccles, Wigfield, Harold, \& Blumenfeld (1993). Further light may be shed on this observation by the stereotype threat girls are victims of and the behaviors ensuing from it, namely, their preference for careers with little mathematics (Plante, Théorêt, \& Favreau, 2010).

A second worthwhile observation relates to the "negative self-talk" subscale. In fact, this subscale maintains the strongest relationships with both anxiety and performance. On this point, we should remember that while negative self-talk accounts for no more than $2 \%$ in students' math performance-previous math performance $\left(\mathrm{R}^{2}=7 \%\right)$ remaining the strongest predictor-it nevertheless explains $26 \%$ of students' levels of anxiety in math tests and in problem-solving. This suggests that helping students not to dwell on problems, catastrophize or feel hopeless would decrease their levels of anxiety and, to a lesser extent, improve their math performance. Such findings would argue in favor of an intervention aiming to develop students' emotional competencies, that is, teach students how to identify their emotions (identification), how to interpret the information conveyed by their emotions (comprehension), how to express their emotions (expression), how to control them (regulation), and how to use them (utilization) (Mayer \& Salovey, 1997; Mikolajczak, 2009).

\section{General Discussion and Conclusion}

This set of studies represents the most systematic published psychometric analysis of a questionnaire within the children's emotion regulation research field. What is more, it constitutes the first attempt to develop an instrument that both takes into account the various existing theoretical approaches in this area and that also reflects the reality of elementary students' emotion regulation. The present results provide modest but encouraging evidence in favor of the validity, reliability and usefulness of the CERS-M.

What stood out, from both studies, was that neither the bipolar distinction-functional versus dysfunctional strategies, nor the 19 factor structure model was suited for 5 th and 6th graders. Rather, the findings emphasized that the latter discriminate between six strategies, that is, task utility self-persuasion, emotion expression, help seeking, brief attentional relaxation, negative self-talk, and dysfunctional avoidance. In addition, both studies shed light on the way fifth and sixth graders regulate their negative emotions when dealing with problem-solving tasks. First, if on the whole, emotion regulation strategies are only used from time to time, one strategy stands out by virtue of being most often 
used; this is "task utility self-persuasion". This consists in motivational reflection focused on the task and, as such, deals with unpleasant emotions in a "colder" way than the least used strategies (i.e. emotion expression, negative self-talk, dysfunctional avoidance and brief attentional relaxation). These handle unpleasant emotions in a "hot" way, that is, by focusing on listening to one's emotions. Second, the factor structure analysis pointed out that emotion expression is considered by upper elementary students as dysfunctional while this strategy appears among the functional strategies within the theoretical model. These two observations give credibility to the idea that there is no place for the learner's feelings in mathematics. Third, the negative self-talk strategy stood out as predicting a substantial part of student anxiety. All these findings support the need to integrate within the math class a sequence of lessons on emotional competencies with a special focus on emotion regulation.

Several limitations do have to be acknowledged. First, participants were $5^{\text {th }}$ and $6^{\text {th }}$ graders, which restrict range and generalization, both regarding age and students' emotional relationship to mathematics. Therefore, future research should be extended to other grades and to secondary level. For instance, it would be interesting to validate the CERS-M with two kinds of secondary students samples: one with secondary 1 students to test the influence of the transition from primary school through secondary school, and the other with secondary 3 students to highlight the major changes regarding emotion regulation that operate during adolescence. Second, it would be interesting to develop the findings regarding performance by examining variables that are at the same time strongly associated with performance and in a non-ambivalent way to emotion regulation, such as the way students process information (superficial versus in-depth), the way students regulate their learning (self-regulation versus external guidance) and the kind of cognitive strategies used (i.e. among a list of problem-solving heuristics) (Pekrun, 2006). In the same vein, in order to provide additional evidence of the validity of the CERS-M, future studies should be set up to study the predictive power of the CERS-M on dimensions for which a relation with emotion regulation has been demonstrated (e.g. the propensity to experience various discrete emotions, happiness and mental health, Nelis et al. (2011)). Fourth, all study variables were measured through self-reported evaluations and this may have caused a certain bias. In effect, because of the retrospective character of such instruments (Cleary, 2011; Greene, Robertson, \& Croker Costa, 2011) and their sensibility to social desirability (Perry \& Winne, 2006; Winne \& Perry, 2000), students may have under- or over-estimated their level of anxiety or the extent to which they used emotion regulation strategies in math problem-solving. So in order to overcome the social desirability bias, future studies should be launched to examine the susceptibility of CERS-M responses to social desirability. In sum, although these exploratory findings call for replication, they supply preliminary evidence that the CERS-M can be a valuable tool for clinical, educational and research purposes. 


\section{Acknowledgements}

The authors would like to thank all the children and teachers who participated in this study. We would like to offer special thanks to the teachers in "Hautes Ecoles" for helping us to collect these data.

\section{References}

Ahmed, W., Minnaert, A., Van der Werf, G., \& Kuyper, H. (2013). Emotions, Self-Regulated Learning, and Achievement in Mathematics: A Growth Curve Analysis. Journal of Educational Psychology, 105, 150-161. https://doi.org/10.1037/a0030160

Ambady, N., Shih, M., Kim, A., \& Pittinsky, T. L. (2001). Stereotype Susceptibility in Children: Effects of Identity Activation on Quantitative Performance. Psychological science, 12, 385-390. https://doi.org/10.1111/1467-9280.00371

Amstadter, A. (2008). Emotion Regulation and Anxiety Disorders, Anxiety Disorders, 22, 211-221. https://doi.org/10.1016/j.janxdis.2007.02.004

Ayers, T. S., Sandler, I. N., West, S. G., \& Roosa, M. W. (1996). A Dispositional and Situational Assessment of Children's Coping: Testing Alternative Models of Coping. Journal of Personality, 64, 923-958. https://doi.org/10.1111/j.1467-6494.1996.tb00949.x

Belgian Official Gazette (2009). Décret de la Communautéfrançaise du 30 avril 2009 organisant un encadrementdifférencié au sein des établissementsscolaires de la Communautéfrançaiseafind'assurer à chaqueélève des chances égalesd'émancipationsociale dans un environnementpédagogique de qualité. [Decree of the French Community of 30 April 2009 Organizing a Differentiated Scaffolding within the Schools of the French Community in Order to Ensure Each Pupil Equal Opportunities of Social Emancipation in a Quality Pedagogical Environment.] 9 July, p. 34295.

Borkovec, T. D., Ray, W. J., \& Stober, J. (1998). Worry: A Cognitive Phenomenon Intimately Linked to Affective, Physiological, and Interpersonal Behavioral Processes. Cognitive Therapy and Research, 22, 561-576. https://doi.org/10.1023/A:1018790003416

Brody, L. R. (2000). On Understanding Gender Differences in the Expression of Emotion. Gender Roles, Socialization, and Language. In S. L. Ablon, D. Brown, E. J. Khantzian, \& J. E. Mack (Eds.), Human Feelings: Exploration in Affect Development and Meaning (pp. 87-126). Hillsdale, NJ: The Analytic Press.

Brown, T. (2006). Confirmatory Factor Analysis for Applied Research. New York, NY: Guilford Press.

Bryant, F. B. (2000). Assessing the Validity of Measurement. In G. Laurence, P. R. Yarnold (Eds.), Reading and Understanding More Multivariate Statistics (pp. 99-146). Washington DC: American Psychology Association.

Byrne, B. M. (2016). Structural Equation Modeling with AMOS: Basic Concepts, Applications, and Programming (3rd Edition). New York: Routledge.

Carver, C. S., Scheier, M. F., \& Weintraub, J. K. (1989). Assessing Coping Strategies: A Theoretically Based Approach. Journal of Personality and Social Psychology, 56, 267-283. https://doi.org/10.1037/0022-3514.56.2.267

Cleary, T. J. (2011). Emergence of Self-Regulated Learning Microanalysis. Historical Overview, Essential Features, and Implications for Research and Practice. In B. Zimmerman \& D. Schunk (Eds.), Handbook of Self-Regulation of Learning and Performance (pp. 329-345). New York: Routledge.

De Corte, E., Depaepe, F., Op't Eynde, P., \& Verschaffel, L. (2011). Students' 
Self-Regulation of Emotions in Mathematics: An Analysis of Meta-Emotional Knowledge and Skills. ZDM Mathematics Education, 43, 483-495.

https://doi.org/10.1007/s11858-011-0333-6

Denham, S. A., McKinley, M., Couchoud, E. A., \& Holt, R. (1990). Emotional and Behavioral Predictors of Preschool Peer Ratings. Child Development, 61, 1145-1152. https://doi.org/10.2307/1130882

Desmarets, A., Jadin, B., Rouche, N., \& Sartiaux, P. (1997). Oh, moi les maths... [Oh, Me and Math...]. Soignies: Talus d'approche.

Di Fabio, A., \& Palazzeschi, L. (2009). An In-Depth Look at Scholastic Success: Fluid Intelligence, Personality Traits or Emotional Intelligence? Personality and Individual Differences, 46, 581-585. https://doi.org/10.1016/j.paid.2008.12.012

Eccles, J., Wigfield, A., Harold, R. D., \& Blumenfeld, P. (1993). Age and Gender Differences in Children's Self- and Task Perceptions during Elementary School. Child Development, 64, 830-847.

Eisenberg, N., Cumberland, A., Spinrad, T. L., Fabes, R. A., Shepard, S. A. et al. (2001). The Relations of Regulation and Emotionality to Children's Externalizing and Internalizing Problem Behavior. Child Development, 72, 1112-1134. https://doi.org/10.1111/1467-8624.00337

Endler, N. S., \& Parker, J. D. (1990). Multidimensional Assessment of Coping: A Critical Evaluation. Journal of Personality and Social Psychology, 58, 844-854. https://doi.org/10.1037/0022-3514.58.5.844

Extremera, N., Duran, A., \& Rey, L. (2007). Perceived Emotional Intelligence and Dispositional Optimism-Pessimism: Analyzing Their Role in Predicting Psychological Adjustment among Adolescents. Personality and Individual Differences, 42, 1069-1079. https://doi.org/10.1016/j.paid.2006.09.014

Fagnant, A., \& Demonty, I. (2005). Résoudre des problèmes: pas de problème ! Guide méthodologique et documents reproductibles. 10/12ans [To Solve Problems: No Problem! Methodological Guide and Reproducible Documents. 10/12 Years]. Brussels: De Boeck.

Field, A. (2009). Discovering Statistics Using SPSS (3rd Edition). London: SAGE.

Fredrickson, B. L., Mancuso, R. A., Branigan, C., \& Tugade, M. M. (2000). The Undoing Effect of Positive Emotions. Motivation and Emotion, 34, 237-258. https://doi.org/10.1023/A:1010796329158

Freud, S. (1896/2000). Nouvelles remarques sur les psychonévroses de défense [New Comments on the Defensepsychoneuroses]. In J. Bourguignon \& P. Cotet (Eds.), Sigmund Freud: Euvrescomplètes [Sigmund Freud: Complete Works], (Vol. 3, pp. 121-146). Paris: Presses Universitaires de France.

Freudenthaler, H. H., \& Neubauer, A. C. (2005). Emotional Intelligence. The Convergent and Discriminant Validities of Intra and Interpersonal Emotional Abilities. Personality and Individual Differences, 39, 569-579. https://doi.org/10.1016/j.paid.2005.02.004

Freudenthaler, H. H., \& Neubauer, A. C. (2007). Measuring Emotional Management Abilities: Further Evidence of the Importance to Distinguish between Typical and Maximum Performance. Personality and Individual Differences, 42, 1561-1572. https://doi.org/10.1016/j.paid.2006.10.031

Frijda, N. H. (1986). The Emotions. Cambridge \& New York: Cambridge University Press.

Frijda, N. H. (1993). Mood, Emotion Episodes, and Emotions. In M. Lewis, \& J. M. Haviland (Eds.), Handbook of Emotions (pp. 381-403). New York, NY: Guilford Press. 
Garnefski, N., \& Kraaij, V. (2007). The Cognitive Emotion Regulation Questionnaire. European Journal of Psychological Assessment, 23, 141-149.

https://doi.org/10.1027/1015-5759.23.3.141

Garnefski, N., Kraaij, V., \& Spinhoven, P. (2001). Negative Life Events, Cognitive Emotion Regulation and Emotional Problems. Personality and Individual Differences, 30, 1311-1327. https://doi.org/10.1016/S0191-8869(00)00113-6

Garnefski, N., Rieffe, C., Jellesma, F., Terwogt, M. M., \& Kraaij, V. (2007). Cognitive Emotion Regulation Strategies and Emotional Problems in 9 - 11-Year-Old Children. European Child \& Adolescent Psychiatry, 16, 1-9. https://doi.org/10.1007/s00787-006-0562-3

Goetz, T., Frenzel, A. C., Pekrun, R., \& Hall, N. C. (2006). The Domain Specificity of Academic Emotional Experiences. The Journal of Experimental Education, 75, 5-29. https://doi.org/10.3200/JEXE.75.1.5-29

Goetz, T., Frenzel, A. C., Pekrun, R., Hall, N. C., \& Lüdtke, O. (2007). Between and within Domain Relations of Students' Academic Emotions. Journal of Educational Psychology, 99, 715-733. https://doi.org/10.1037/0022-0663.99.4.715

Goetz, T., Haag, L., Lipnevitch, A. A., Keller, M. M., Frenzel, A. C., \& Collier, P. M. (2014). Between-Domain Relations of Students' Academic Emotions and Their Judgments of School Domain Similarity. Frontiers in Psychology, 5, 1-14.

https://doi.org/10.3389/fpsyg.2014.01153

Goetz, T., Pekrun, R., Hall, N., \& Haag, L. (2006). Academic Emotions from a Social-Cognitive Perspective: Antecedents and Domain Specificity of Students' Affect in the Context of Latin Instruction. British Journal of Educational Psychology, 76, 289-308. https://doi.org/10.1348/000709905X42860

Gravetter, F., \& Wallnau, L. (2014). Essentials of Statistics for the Behavioral Sciences (8th Edition). Belmont, CA: Wadsworth.

Greene, J. A., Robertson, J., \& Croker Costa, L.-J. (2011). Assessing Self-Regulated Learning Using Think-Aloud Methods. In B. Zimmerman, \& D. Schunk (Eds.), Handbook of Self-Regulation of Learning and Performance (pp. 313-328). New-York: Routledge.

Gross, J. J. \& Munoz, R. F. (1995). Emotion Regulation and Mental Health. Clinical Psychology: Science and Practice, 2, 151-164. https://doi.org/10.1111/j.1468-2850.1995.tb00036.x

Gross, J. J. (1998). The Emerging Field of Emotion Regulation: An Integrative Review. Review of General Psychology, 2, 271-299. https://doi.org/10.1037/1089-2680.2.3.271

Hanin, V., \& Van Nieuwenhoven, C. (2016). The Influence of Motivational and Emotional Factors in Mathematical Learning in Secondary Education. European Review of Applied Psychology, 66, 127-138. https://doi.org/10.1016/j.erap.2016.04.006

Hayton, J. C., Allen, D. G., \& Scarpello, V. (2004). Factor Retention Decisions in Exploratory Analysis: A Tutorial on Parallel Analysis. Organizational Research Methods, 7, 191-205. https://doi.org/10.1177/1094428104263675

Hopko, D. R., Mahadevan, R., Bare, R. L., \& Hunt, M. K. (2003). The Abbreviate Math Anxiety Scale (AMAS). Construction, Validity, and Reliability. Assessment, 10, 178-182. https://doi.org/10.1177/1073191103010002008

Housiaux, M., Luminet, O., Van Broeck, N., \& Dorchy, H. (2010). Alexithymia Is Associated with Glycaemic Control of Children with Type 1 Diabetes. Diabetes \& Metabolism, 36, 455-462. https://doi.org/10.1016/j.diabet.2010.06.004

Hu, L. T., \& Bentler, P. M. (1999). Cutoff Criteria for Fit Indexes in Covariance Structure Analysis: Conventional Criteria versus New Alternatives. Structural Equation Model- 
ing: A Multidisciplinary Journal, 6, 1-55. https://doi.org/10.1080/10705519909540118

Isen, A. M. (2000). Some Perspectives on Positive Affect and Self-Regulation. Psychological Inquiry, 11, 184-187.

Jordan, J. A., McRorie, M., \& Ewing, C. (2010). Gender Differences in the Role of Emotional Intelligence during the Primary-Secondary School Transition. Emotional and Behavioral Difficulties, 15, 37-47. https://doi.org/10.1080/13632750903512415

Joukamaa, M., Taanila, A., Miettunen, J., Karvonen, J. T., Koskinen, M., \& Veijola, J. (2007). Epidemiology of Alexithymia among Adolescents. Journal of Psychosomatic Research, 63, 373-376. https://doi.org/10.1016/j.jpsychores.2007.01.018

Laveault, D., \& Grégoire, J. (2014). Introduction aux théories des tests en psychologie et en sciences de l'éducation [Introduction to the Theories of Tests in Psychology and Sciences of Education] (3rd Edition). Brussels: De Boeck.

Lazarus, R. S., \& Folkman, S. (1984). Stress, Appraisal, and Coping. New York: Springer Publishing Company.

Lecocq, P. (1996). L'E.C.O.S.S.E une épreuve de compréhension syntaxico-sémantique (manuel et épreuve) [A Syntactico-Semantic Test (Manual and Test)]. Lille, France: Presses Universitaires du Septentrion.

Leroy, V., Boudrenghien, G., \& Grégoire, J. (2013). Une adaptation française du Questionnaire de Régulation Émotionnelle à la situation d'apprentissage [A French Adaptation of the Emotion Regulation Questionnaire to the Learning Situation]. Mesure et évaluation en éducation, 36, 27-48. https://doi.org/10.7202/1024464ar

Levant, R. F., Hall, R. J., Williams, C. M., \& Hasan, N. T. (2009). Gender Differences in Alexithymia. Psychology of Men \& Masculinity, 10, 190-203. https://doi.org/10.1037/a0015652

Linnenbrink, E. A. (2006). Emotion Research in Education: Theoretical and Methodological Perspectives on the Integration of Affect, Motivation, and Cognition. Educational Psychology Review, 18, 307-314. https://doi.org/10.1007/s10648-006-9028-x

MacCann, C., Roberts, R. D., Matthews, G., \& Zeidner, M. (2004). Consensus Scoring and Empirical Option Weighting of Performance-Based Emotional Intelligence (EI) Tests. Personality and Individual Differences, 36, 645-662. https://doi.org/10.1016/S0191-8869(03)00123-5

Mavroveli, S., Petrides, K., \& Shove, C., \& Whitehead, A. (2008). Investigation of the Construct of Trait Emotional Intelligence in Children. European Child \& Adolescent Psychiatry, 17, 516-526. https://doi.org/10.1007/s00787-008-0696-6

Mayer, J. D., \& Salovey, P. (1997). What Is Emotional Intelligence? In P. Salovey, \& D. Sluyter (Eds.), Emotional Development and Emotional Intelligence: Implications for Educators (pp. 3-31). New York: Basic Books.

Mayer, J. D., Salovey, P., \& Caruso, D. R. (2002). Mayer-Salovey-Caruso Emotional Intelligence Test (MSCEIT) User's Manual. Toronto, Ontario, Canada: MHS Publishers.

Messick, S. (1995). Validity of Psychological Assessment: Validation of Inferences from Persons' Responses and Performances as Scientific Inquiry into Score Meaning. American Psychologist, 50, 741-749. https://doi.org/10.1037/0003-066X.50.9.741

Mikolajczak, M. (2012). Chapitre 9. Approche empirique (anc. cognitive et comportementale) de la régulation des émotions [Chapter 9. Empirical Approach (Cognitive and Behavioral) of Emotion Regulation]. In M. Mikolajczak, \& M. Desseilles (Eds.), Traité de régulation des émotions [Emotion Regulation Treaty] (pp. 149-168). Brussels: De Boeck.

Mikolajczak, M., Luminet, O., Leroy, C., \& Roy, E. (2007). Psychometric Properties of the 
Trait Emotional Intelligence Questionnaire: Factor Structure, Reliability, Construct, and Incremental Validity in a French-Speaking Population. Journal of Personality Assessment, 88, 338-353. https://doi.org/10.1080/00223890701333431

Mikolajczak, M., Quoidbach, J., Kotsou, I., \& Nélis, D. (2009). Les compétences émotionnelles [Emotional Competence]. Paris: Dunod.

Nelis, D., Quoidbach, J., Hansenne, M., \& Mikolajczak, M. (2011). Measuring Individual Differences in Emotion Regulation: The Emotion Regulation Profile-Revised (ERP-R). Psychologica Belgica, 51, 49-91. https://doi.org/10.5334/pb-51-1-49

Nyroos, M., Korhonen, J., Linnanmäki, K., \& Svens-Liavag C. (2012). A Cross-National Comparison of Test Anxiety in Swedish and Finnish Grade 3 Pupils: Measured by the CTAS. Education Inquiry, 3, 615-636. https://doi.org/10.3402/edui.v3i4.22057

OECD (2014). Pisa 2012 Results: What Students Know and Can Do. Student Performance in Mathematics, Reading and Science (Volume 1, Revised Edition). Paris: OECD Publishing.

OECD (2016). Pisa 2015 Results: Policies and Practices for Successful Schools (Volume 2). Paris: OECD Publishing. https://doi.org/10.1787/aa9237e6-en

Op't Eynde, P., De Corte, E., \& Mercken, I. (2004). Pupils (Meta)Emotional Knowledge and Skills in the Mathematics Classroom. Unpublished Document Presented at the American Educational Research Association (AERA), San Diego.

Op't Eynde, P., De Corte, E., \& Verschaffel, L. (2006). Accepting Emotional Complexity: A Socio-Constructivist Perspective on the Role of Emotions in the Mathematics Classroom. Educational Studies in Mathematics, 63, 193-207.

https://doi.org/10.1007/s10649-006-9034-4

Pallascio, R., \& Lafortune, L. (2000). Pour une pensée réflexive en éducation [For a Reflexive Thought in Education]. Québec: Presses de l'Université du Québec.

Parkinson, B., \& Totterdell, P. (1999). Classifying Affect-Regulation Strategies. Cognition and Emotion, 13, 277-303. https://doi.org/10.1080/026999399379285

Pekrun, R. (2006). The Control-Value Theory of Achievement Emotions: Assumptions, Corollaries, and Implications for Educational Research and Practice. Educational Psychology Review, 18, 315-341. https://doi.org/10.1007/s10648-006-9029-9

Perry, N. E., \& Winne, P. H. (2006). Learning from Learning Kits: gStudy Traces of Students Self-Regulated Engagement with Computerized Content. Educational Psychology Review, 18, 211-228. https://doi.org/10.1007/s10648-006-9014-3

Petrides, K. V., Frederickson, N., \& Furnham, A. (2004). The Role of Trait Emotional Intelligence in Academic Performance and Deviant Behavior at School. Personality and Individual Differences, 36, 277-293. https://doi.org/10.1016/S0191-8869(03)00084-9

Plante, I., Théorêt, M., \& Favreau, O. E. (2010). Les stéréotypes de genre en mathématiques et en langues: recension critique en regard de la réussite scolaire [Gender Stereotypes in Mathematics and Languages: Critical Review of Academic Achievement]. Revue des sciences de l'éducation, 36, 389-419.

https://doi.org/10.7202/044483ar

Pons, F., Doudin, P.-A, Harris, P. L., \& de Rosnay, M. (2002). Métaémotion et intégration scolaire [Metaemotion and School Integration]. In L. Lafortune, \& P. Mongeau (Eds.), L'affectivité dans l'apprentissage [Affectivity in Learning] (pp. 7-28). Sainte-Foy: Presses de l'Université du Québec.

Rieffe, C., Terwogt, M. M., Petrides, K. V., Cowan, R., Miers, A. C. et al. (2007). Psychometric Properties of the Emotion Awareness Questionnaire for Children. Personality and Individual Differences, 43, 95-105. https://doi.org/10.1016/j.paid.2006.11.015 
Rimé, B. (2005). Le partage social des émotions [Social Sharing of Emotion]. Paris: Presses Universitaires de France.

Schulte, M. J., Ree, M. J., \& Carretta, T. R. (2004). Emotional Intelligence: Not Much More than $g$ and Personality. Personality and Individual Differences, 37, 1059-1068. https://doi.org/10.1016/j.paid.2003.11.014

Van der Zee, K., Thijs, M., \& Schakel, L. (2002). The Relationship of Emotional Intelligence with Academic Intelligence and the Big Five. European Journal of Personality, 16, 103-125. https://doi.org/10.1002/per.434

Winne, P. H., \& Perry, N. E. (2000). Measuring Self-Regulated Learning. In M. Boekaerts, P. R. Pintrich, \& M. Zeidner (Eds.), Handbook of Self-Regulation: Theory, Research, and Applications (pp. 750-768). San Diego, CA: Academic Press.

https://doi.org/10.1016/B978-012109890-2/50045-7 


\title{
Appendix A. Analysis of the CERQ-Child's, the COPE's and the CERS-M's Subscales in the Light of the Components of the Emotion Generative Process as Defined by Gross (1998)
}

\author{
Component of the \\ emotion generative \\ process (Gross, 1998; \\ Mikolajczak, 2012) \\ Subscales of the CERQ-Child \\ (Garnefski et al., 2007) \\ Subscales of the COPE-questionnaire \\ (De Corte et al., 2011) \\ Subscales of the CERS-M
}

Situation selection

\author{
- Planning (e.g. "I think about \\ what would be the best for me \\ to do")
}

Situation modification
Cognitive change

Response modulation

Emotion expression
- Active coping (e.g. "I concentrate my efforts on doing something about the problem") steps to take")

- Restraint coping (e.g. "I'm not doing anything until the time is right")

- Seeking support for instrumental reasons (e.g. "I ask people who have had similar experiences what they did")

- Rumination (e.g. "Again and - Suppression of competing activities again, I think of how I feel about it")

- Positive refocusing (e.g. "I think of nicer things that have nothing to do with it") problem and I put the other things on the side")

- Denial (e.g. "I say to myself that it is not true") - Planning (e.g. "I think hard about what (e.g. "I concentrate on the resolution of the

- Mental disengagement (e.g. "I dream about things other than this")

- Behavioral disengagement (e.g. "I give up trying to reach my goal")

- Turning to religion (e.g. "I believe in God's help")

- Positive reappraisal (e.g. "I think that I can learn from it")

- Putting into perspective (e.g.

"I think that worse things can happen")

- Other-blame (e.g. "I think

that others are to blame")

- Self-blame (e.g. "I think that I am to blame")

- Catastrophizing (e.g. "I often think that it's much worse than what happens to others")

- Acceptance (e.g. "I think that

I have to accept it")
- Positive reinterpretation and growth

(e.g. "I look for something positive in what is happening")

- Acceptance (e.g. "I accept the fact that it happens")

- Joking (e.g. "I laugh at the situation")
- Task utility self-persuasion (e.g. "Even if I do not like it very much, I still try to solve the problem because it is useful for me").

- Dysfunctional avoidance (e.g. "In order not to live through an unpleasant time, I tell myself that I will solve the problem later")

Help seeking (e.g. "I ask the teacher to help me to solve the problem")

- Negative self-talk (e.g., "I say to myself that I have always had difficulty in solving math problems and that it is not going to change")

Brief attentional relaxation (e.g. "I take small breaks -looking out the window, breathing deeply, etc. - when I solve math problems")

- Negative self-talk (e.g. "I'm focusing on the anger, sadness, boredom or despair that I feel and I can no longer continue to solve the problem")

- Task utility self-persuasion (e.g. "Even if I dislike solving math problems, I tell myself that it is important to do so in order to be able to understand them and thereby to succeed"). - Negative self-talk (e.g., "I tell myself that it is terrible not being able to solve the problem and that I am sure that it only happens to me")
- Brief attentional relaxation (e.g. "I put down my pen a few seconds and stretch my arms").

- Emotion expression (e.g. "I tell my neighbor that the problem makes me angry, sad, hopeless, or bored")
- Alcohol-drug disengagement (e.g. "I consume alcohol or drugs to feel better")

- Seeking support for emotional reasons (e.g. "I talk to someone about how I feel") - Seeking support for instrumental reasons (e.g. "I ask people who have had similar experiences what they did")

- Focus on and venting emotions (e.g. "I am upset and I express my emotions")

Note. Strategies in italic aren't appropriate for elementary and secondary students. 


\section{Appendix B. French Version of the Six-Factor CERS-M (Items with an Asterisk Have been Removed Further to the Analysis of Internal Consistency Conducted in Study 2)}

\section{Emotion expression}

1) Je dis à mon voisin/ma voisine que le problème me met en colère, me rend triste, me désespère ou m'ennuie.

2) Je dis à un autre élève que le problème me met de mauvaise humeur.

3) Je me plains à haute voix que le problème est trop compliqué*.

\section{Task utility self-persuasion}

1) Même si je n'aime pas les problèmes en math, je me dis que c'est bien de les faire pour pouvoir les comprendre et réussir.

2) Même si je n'aime pas beaucoup, j'essaie quand même de résoudre le problème car je trouve cela utile pour moi.

3) Je me concentre fort sur le problème pour essayer de le résoudre*.

\section{Negative self-talk}

1) Je me dis qu'il n'y a sûrement que moi qui n'arrive pas à résoudre le problème et qui me sens aussi mal.

2) Je me dis que c'est épouvantable de ne pas être capable de résoudre le problème, que je suis sûr(e) que ça n'arrive qu'à moi.

3) Je me dis que j'ai toujours difficile à faire des problèmes en math et que cela ne va pas changer.

\section{Help seeking}

1) Je demande de l'aide à l'instituteur pour résoudre le problème.

2) Je demande à l'instituteur qu'il m'explique le problème.

3) Je refuse l'aide de l'instituteur ou de mon voisin quand ils proposent de m'expliquer le problème*.

\section{Brief attentional relaxation}

1) Quand je résous un problème en math, je m'arrête de temps en temps pour me détendre avant de poursuivre.

2) Je fais des petites pauses (regarder par la fenêtre, respirer profondément, ...) quand je résous un problème en math.

3) Je dépose mon stylo quelques secondes et m'étire les bras.

\section{Dysfunctional avoidance}

1) Pour ne pas vivre un moment désagréable, je me dis que je résoudrai plus tard les problèmes.

2) Il m'arrive souvent de remettre à après les problèmes à résoudre pour éviter de me sentir mal.

3) Comme les problèmes en math me mettent en colère, me rendent triste, me désespèrent ou m'ennuient, je préfère ne pas les faire*. 